NASA/TM-1999-209830

ARL-TR-2110
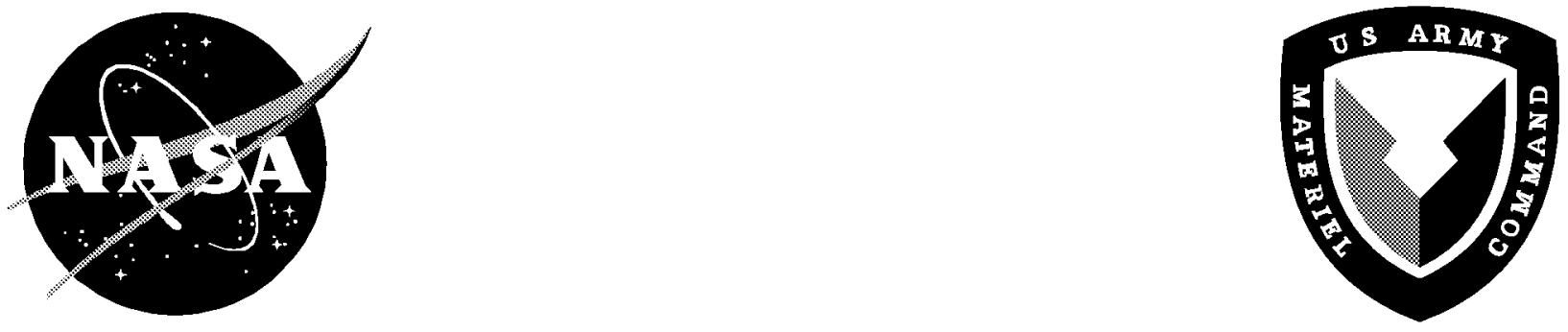

\title{
Influence of Ply Waviness on Fatigue Life of Tapered Composite Flexbeam Laminates
}

Gretchen B. Murri

U. S. Army Research Laboratory

Vehicle Technology Directorate

Langley Research Center, Hampton, Virginia 


\section{The NASA STI Program Office ... in Profile}

Since its founding, NASA has been dedicated to the advancement of aeronautics and space science. The NASA Scientific and Technical Information (STI) Program Office plays a key part in helping NASA maintain this important role.

The NASA STI Program Office is operated by Langley Research Center, the lead center for NASA's scientific and technical information. The NASA STI Program Office provides access to the NASA STI Database, the largest collection of aeronautical and space science STI in the world. The Program Office is also NASA's institutional mechanism for disseminating the results of its research and development activities. These results are published by NASA in the NASA STI Report Series, which includes the following report types:

- TECHNICAL PUBLICATION. Reports of completed research or a major significant phase of research that present the results of NASA programs and include extensive data or theoretical analysis. Includes compilations of significant scientific and technical data and information deemed to be of continuing reference value. NASA counterpart of peer-reviewed formal professional papers, but having less stringent limitations on manuscript length and extent of graphic presentations.

- TECHNICAL MEMORANDUM. Scientific and technical findings that are preliminary or of specialized interest, e.g., quick release reports, working papers, and bibliographies that contain minimal annotation. Does not contain extensive analysis.

- CONTRACTOR REPORT. Scientific and technical findings by NASA-sponsored contractors and grantees.
- CONFERENCE PUBLICATION. Collected papers from scientific and technical conferences, symposia, seminars, or other meetings sponsored or co-sponsored by NASA.

- SPECIAL PUBLICATION. Scientific, technical, or historical information from NASA programs, projects, and missions, often concerned with subjects having substantial public interest.

- TECHNICAL TRANSLATION. Englishlanguage translations of foreign scientific and technical material pertinent to NASA's mission.

Specialized services that complement the STI Program Office's diverse offerings include creating custom thesauri, building customized databases, organizing and publishing research results ... even providing videos.

For more information about the NASA STI Program Office, see the following:

- Access the NASA STI Program Home Page at http://www.sti.nasa.gov

- Email your question via the Internet to help@sti.nasa.gov

- Fax your question to the NASA STI Help Desk at (301) 621-0134

- Telephone the NASA STI Help Desk at (301) 621-0390

- Write to: NASA STI Help Desk NASA Center for AeroSpace Information 7121 Standard Drive Hanover, MD 21076-1320 
NASA/TM-1999-209830

ARL-TR-2110
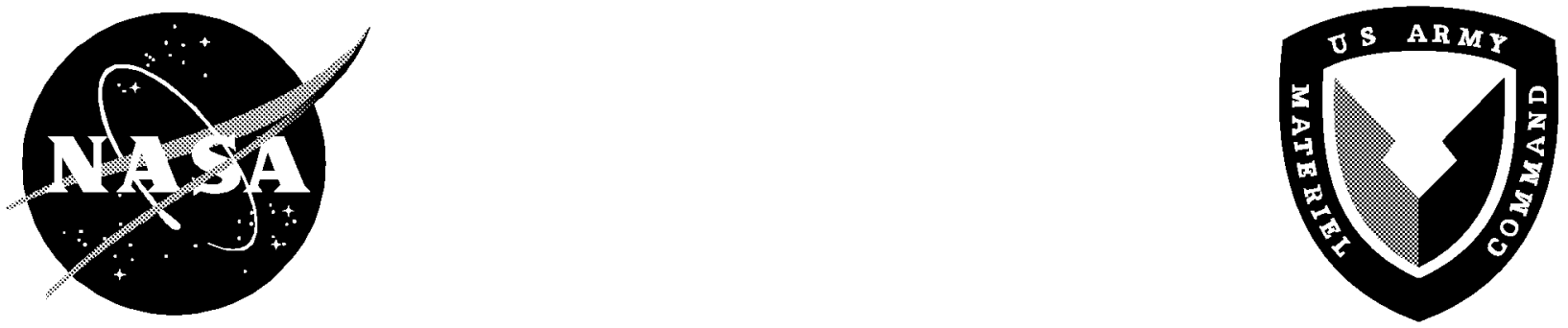

\section{Influence of Ply Waviness on Fatigue Life of Tapered Composite Flexbeam Laminates}

Gretchen B. Murri

U. S. Army Research Laboratory

Vehicle Technology Directorate

Langley Research Center, Hampton, Virginia

National Aeronautics and

Space Administration

Langley Research Center

Hampton, Virginia 23681-2199 
The use of trademarks or names of manufacturers in this report is for accurate reporting and does not constitute an official endorsement, either expressed or implied, of such products or manufacturers by the National Aeronautics and Space Administration or the U.S. Army.

Available from:

NASA Center for AeroSpace Information (CASI) 7121 Standard Drive

Hanover, MD 21076-1320

(301) 621-0390
National Technical Information Service (NTIS) 5285 Port Royal Road

Springfield, VA 22161-2171

(703) 605-6000 


\begin{abstract}
Nonlinear tapered flexbeam laminates, with significant ply waviness, were cut from a fullsize composite rotor hub flexbeam. The specimens were tested under combined axial tension and cyclic bending loads. All of the specimens had wavy plies through the center and near the surfaces (termed marcelled areas), although for some of the specimens the surface marcels were very obvious, and for others they were much smaller. The specimens failed by first developing cracks through the marcels at the surfaces, and then delaminations grew from those cracks, in both directions. Delamination failure occurred in these specimens at significantly shorter fatigue lives than similar specimens without waviness, tested in ref. 2.

A 2D finite element model was developed which closely approximated the flexbeam geometry, boundary conditions, and loading. In addition, the FE model duplicated the waviness observed in one of the test specimens. The model was analyzed using a geometrically nonlinear FE code. Modifications were made to the original model to reduce the amplitude of the marcels near the surfaces. The analysis was repeated for each modification. Comparisons of the interlaminar normal stresses, $\sigma_{n}$, in the various models showed that under combined axial-tension and cyclic-bending loading, for marcels of the same aspect ratio, $\sigma_{n}$ stresses increased as the distance along the taper, from thick to thin end, increased. For marcels of the same aspect ratio and at the same x-location along the taper, $\sigma_{n}$ stresses decreased as the distance from the surface into the flexbeam interior increased. A technique was presented for determining the smallest acceptable marcel aspect ratio at various locations in the flexbeam.
\end{abstract}

\title{
NOMENCLATURE
}

\begin{tabular}{|c|c|}
\hline $\begin{array}{l}E_{11}, E_{22} \\
G_{12}\end{array}$ & $\begin{array}{l}\text { Young's moduli in the 1- and 2- directions, GPa } \\
\text { shear modulus, GPa }\end{array}$ \\
\hline & period of one marcel, $\mathrm{mm}$ \\
\hline & number of loading cycles \\
\hline $\begin{array}{l}P \\
t(x)\end{array}$ & $\begin{array}{l}\text { axial tension load, } \mathrm{kN} \\
\text { flexbeam half-thickness at distance } \mathrm{x} \text { from fixed end } \mathrm{mm}\end{array}$ \\
\hline$v^{(x)}$ & transverse bending load, $\mathrm{kN}$ \\
\hline $\mathrm{v}$ & transverse displacement at tip of flexbeam, $\mathrm{mm}$ \\
\hline $\bar{y}$ & vertical distance from flexbeam surface, $\mathrm{mm}$ \\
\hline$\alpha$ & waviness half-amplitude, $\mathrm{mm}$ \\
\hline$\delta$ & transverse stroke of ATB test machine, $\mathrm{mm}$ \\
\hline$\varepsilon$ & flexbeam surface strain \\
\hline$\varepsilon_{\max }$ & maximum cyclic surface strain \\
\hline$\sigma_{\mathrm{n}}$ & interlaminar normal stress in FE model, MPa \\
\hline$v_{12}$ & Poisson's ratio \\
\hline
\end{tabular}

\section{INTRODUCTION}

Tapered laminated composite flexbeams are used in helicopter rotor hubs to reduce weight, drag, and the number of parts in the hub. The taper in these flexbeams is achieved by terminating internal plies along the length. However, the manufacturing procedures 
required by these flexbeams can sometimes cause significant ply waviness throughout the tapered section of the flexbeam.

In this paper the term marcel is used to describe an area where there is a sudden change in the ply direction, similar to a wrinkle in the ply. Because the manufacturing processes cannot always completely eliminate these marcels, the effect of this waviness on the flexbeam durability needs to be determined. Also, such a study on marcelling in flexbeams may be used to develop accept/reject criteria for these flexbeams.

In ref. 1, the effect of ply waviness on pull-off loads in composite hat stringer specimens was studied using the finite element method (FEM). Waviness was simulated in the FE model by an incline in the ply at the initial delamination location. Five different ply waviness angles were studied and the results showed that even mild amounts of waviness could result in significant reduction in stringer pull-off loads.

Reference 2 described a method for determining the fatigue life of tapered composite flexbeam laminates. In that study, $25.4 \mathrm{~mm}$ (1 inch) wide coupon specimens were cut from a full-size flexbeam of S2/E7T1 glass/epoxy. The specimens were tested under combined axial tension and transverse bending loading in a servo-hydraulic load frame, called the Axial-Tension Bending (ATB) machine [2], using a frequency of $3 \mathrm{~Hz}$ and fullyreversed loading $(R=-1)$. Under fatigue loading, delaminations typically initiated in the areas around the ply-drop locations and grew in both directions along the length. Typical fatigue lives were $10^{5}$ to $10^{7}$ cycles.

In the current study, flexbeams of the same geometry, layup, and material, but with significant ply-waviness, were tested in an identical manner to those in ref. 2 . The location of the delamination initiation and the fatigue lives of the wavy flexbeams were studied. A parametric study was also conducted using a finite element (FE) model of the tapered laminate to examine the effect of the severity of the ply waviness at a given location, and the effect of marcels of the same severity at different locations along the taper or throughthe-thickness.

\section{EXPERIMENTS}

\section{Specimen Configuration}

Tests specimens for this study were cut from a full-scale test flexbeam, which was manufactured in a closed-cavity tool. The full-scale test flexbeam and the cut coupon specimens are shown in fig. 1. The full-scale flexbeam was cut in half cross-wise and then each section was cut lengthwise into $25.4 \mathrm{~mm}$-wide coupons, yielding 6 test specimens. The coupons were symmetric with respect to layup and geometry and were designed with a nonlinear taper. The total number of plies in the laminates varied from 145 at the thick end, to 41 plies at the thin end. An idealized view (no waviness) of the cross-section of the upper half of the flexbeam is shown in fig. 2. This figure shows that the laminate had a woven fabric layer on the surface, four continuous "belt" sections, each 4 plies thick, and 4 "dropped-ply" groups, on each side of the midplane. At the midplane was a symmetric ply-group, which was 5 plies thick. Each dropped-ply group had a maximum thickness of 13 plies at the thick-end. The dropped plies were arranged in a non-uniform, staggered manner. The woven fabric on the surface was E-glass/E7T1-2 and the interior plies were of S2/E7T1 tape. Properties for both materials are given in Table 1. The layups and material properties for each ply group shown in the figure are given in Table 2.

Although all six specimens were cut from the same full-size flexbeam, the degree of waviness, and locations of the wavy areas, varied from specimen to specimen. Specimens $1-3$, cut from one side of the flexbeam, had considerably more waviness than 
specimens 4-6, cut from the other side. The ply waviness appeared as isolated areas of marcelling, and as waviness in the ply-groups at the center of the flexbeam. The waviness in the center ply-groups extended through most of the tapered region of the laminate, with the amplitude of the waves highest near the thick end, and gradually decreasing along the length. None of the specimens showed any waviness in the area of the laminate beyond the tip of Dropped-group 2 in fig. 2. An example of both types of wavy areas is shown in an edge view of specimen 1, in fig. 3 . The figure shows the waviness in the center plygroups, and the enlarged photo shows two isolated areas of large amplitude marcels, one near each surface. The amount and type of waviness were fairly consistent on both sides of a given specimen, except for the large marcelled areas near the surfaces, which did not always appear on both sides.

Specimens 1-3, considered "severe" waviness, had waviness through the center-ply groups, as well as isolated areas near the surfaces where very large (high amplitude) marcels existed. Specimens 4-6, considered "moderate" waviness, had wavy plies through the center, but the waviness was of a lower amplitude than for specimens 1-3. Also, specimens 4-6 did not show the isolated areas of large marcels near the surfaces.

Figure 4 shows an edge view of specimen 2, which had several isolated areas of extreme waviness near the surface, shown in the enlarged photos, in addition to the waviness through the center ply-groups. (The circular white marks near the surfaces in the photos are paint marks that were used to position the strain gages.) Since specimen 2 had the most severe waviness of the six specimens, and since the waviness, including the isolated surface marcels, was identical on both sides, specimen 2 was chosen as the basis for the finite element model. Specimen 3 was very similar to specimen 2, but did not have the marcel on the bottom surface in fig. 4.

Figure 5 shows the edge of specimen 4. As the figure shows, the only evidence of ply waviness in this specimen was in the center ply-groups near the thick end. Specimens 5 and 6 were similar to specimen 4 .

\section{Axial Tension Bending Machine}

Specimens were tested under combined axial-tension and transverse-bending loading in the Axial-Tension Bending (ATB) Machine. The ATB, shown in fig. 6, is a servohydraulic load frame, which produces combined tension-bending loading. As fig. 6 shows, the axial load cell is located above the top grip, but below the pivot connecting the axial and transverse actuators. This allows the tension load to rotate with the specimen as the transverse load is applied. Hence, under axial load control, the magnitude of the tension load, $P$, remains constant as the specimen rotates under the transverse-bending displacement, $\delta$. By controlling the axial tension actuator under load control and the transverse bending actuator under stroke control, a constant membrane load should be maintained throughout the loading cycle.

\section{Static Tests}

Initial static testing was conducted to determine the relationship between applied loads and the specimen deflection and surface strains. Specimens were first instrumented with strain gages at five locations along the length on each side: one near the junction of the thick and tapered regions ( 1 and 6), three along the tapered region (2-4 and 7-9), and one in the thin section (5 and 10). Figure 7 shows a schematic of the ATB and flexbeam, rotated $90^{\circ}$ clockwise. The figure shows the numbered gages on each surface of the flexbeam and 
Table 3 lists their location in distance from the fixed end. The specimen was clamped in the grips with the thick end in the fixed bottom grip. The gage length between the grips was $165 \mathrm{~mm}$ (6.5 inches), and the specimen was placed in the grips so that within the gage section there was approximately a $12.7 \mathrm{~mm}(0.5 \mathrm{inch})$ thick region, a $127 \mathrm{~mm}$ (5 inch) tapered region and a $25.4 \mathrm{~mm}$ ( 1 inch) thin region, as shown in fig. 7 . Note also in fig. 7 , that the transverse bending load, $\mathrm{V}$, was not applied at the top of the flexbeam, but was applied at the pivot point, which was $172 \mathrm{~mm}$ above the top grip.

For static excursion tests, a constant axial tension load, $\mathrm{P}$, of approximately $35.6 \mathrm{kN}$ (8000 lbs.) was applied first. Then the bending load, V, was applied, in steps, to produce a transverse stroke, $\delta$, in increments of approximately $2.54 \mathrm{~mm}(0.1$ inch), up to a maximum stroke of $25.4 \mathrm{~mm}$ (1.0 inch). At each transverse load step, the surface strains were recorded, as well as the transverse flexbeam tip-displacement, v. In order to measure the flexbeam tip-displacement, a spring-loaded direct-current differential tranformer (DCDT) was mounted to the side of the load frame. The DCDT detected the displacement of a bracket attached to the centerline of the top grip.

In ref. 2, the peak surface strains in an identical flexbeam without waviness were plotted as a function of applied transverse stroke, $\delta$. The relationship was shown to be linear as long as the axial load is held constant. Similarly, for this study, the peak surface strains were measured at gage 4 in fig. $7(X=98.5 \mathrm{~mm})$. The maximum surface strains are plotted in fig. 8 , as a function of the transverse load, with a constant axial load of $P=8000 \mathrm{lbs}$. The results are shown to be linear for both specimens 2 and 4 (with severe and moderate waviness, respectively).

\section{Fatigue Tests}

Since the boundary conditions of the ATB differ from those of the full-scale flexbeam in the hub, it is more logical to control the fatigue tests to a desired maximum surface strain level, rather than a prescribed transverse deflection. Hence, for each specimen, a maximum strain level for fatigue testing was chosen, and then results of the type shown in fig. 8 were used to select the maximum cyclic transverse stroke, $\delta$ (see fig. 7 ), to apply corresponding to the chosen strain level. The specimens from ref. 2, without wavy plies, were tested at transverse displacements of $27.9 \mathrm{~mm}$ or $30.5 \mathrm{~mm}$, corresponding to maximum surface strains of 0.01 and 0.015 microstrain, respectively. However, because the static testing showed that the wavy specimens were susceptible to delamination at lower strain levels, the maximum strain levels (or maximum cyclic stroke) chosen for cyclic testing of these specimens were somewhat lower than those used for the specimens without ply waviness in ref. 2 . Specimens $2-6$ were fatigue tested at maximum strain levels of 0.0075 to 0.01 microstrain.

In order to make the delamination damage easier to see, specimen edges were coated prior to testing with a thin layer of white paint. A constant tension load of $35.6 \mathrm{kN}$ (8000 lbs.) was applied to the specimen, corresponding to the net axial stress due to the centrifugal force experienced by the full-scale flexbeam. The maximum cyclic transverse load, V, was applied by cycling sinusoidally to the desired maximum transverse stroke, at a frequency of $3 \mathrm{~Hz}$, and using fully-reversed loading $(\mathrm{R}=-1)$. The specimens were cycled until they had extensive delamination damage along the length of the tapered region at one or more locations. Test results are discussed later in this report. 


\section{ANALYSIS}

\section{Finite Element Model}

In order to duplicate the exact geometry of the wavy flexbeams, a software package known as MEGS (Modeling Exact Geometry from Scanned images) was used [4]. With this software, a scanned image of the object to be modeled was used to create a wireframe image, incorporating as many "as manufactured" details as is desired. The wireframe data was then imported into a PATRAN file, to be used as the basis for developing a finite element model of this configuration. Because specimen 2 appeared to have the most severe waviness at locations near the flexbeam surface, as well as wavy plies in the center of the laminate, specimen 2 was chosen for use in the analysis and FE model.

It was also necessary to apply the loads and boundary conditions to the model in a manner that duplicates the configuration of the ATB. A schematic of the configuration to be modeled by FE is shown in fig. 9. Fixed conditions were applied at the thick end of the composite flexbeam. Beyond the thin end of the flexbeam, additional elements were created to represent the upper grip and steel fixture connecting to the pivot point where the transverse load is applied (see fig. 7). The tension and bending loads are applied at the end of the model, rather than at the flexbeam tip. In this way, the loading conditions of the model duplicate the test conditions. Because the bending stiffness of the steel fixtures was two orders of magnitude greater than the flexbeam, the elements at the thin-end that represent the steel loading fixtures were modeled with a rectangular cross-section equal to the thin end of the composite flexbeam. A modulus was chosen such that the bending stiffness, El, was equivalent to the bending stiffness of the actual ATB fixtures of $1.74 \times 10^{6}$ $\mathrm{N}-\mathrm{m}^{2}\left(6.05 \times 10^{8} \mathrm{lb}-\mathrm{in}^{2}\right)$.

\section{Finite Element Mesh and Boundary Conditions}

A 2D finite element model of specimen 2 is shown in fig. 10. The model had a total of 21,903 nodes and 6971 elements in the mesh. Eight-noded quadrilateral and 6-noded triangular plane-strain elements were used. A fine mesh, using one element per plythickness, was used for the ply-groups closest to the surfaces, in the areas around the marcels nearest to the top and bottom surfaces. A coarser mesh was used in the interior of the model and in the thinner region of the flexbeam. In those areas, ply-groups were modeled, rather than individual plies, and smeared properties were used. The smeared moduli in the global $X-Y$ coordinate system are presented in Table 2.

In order to assign appropriate material properties to the wavy plies, a local coordinate system was defined for each element in the model, with the 1-direction parallel to the element side from the local node $i$ to local node $i+1$, as shown in fig. 10 . The local $t-n$ coordinate system was then used to define the material properties of each element. Figure 11 shows enlargements of three marcelled areas near the surface. These have been designated marcels 1-3, as shown. The shaded areas in the enlarged figures represent resin-rich regions. The elements in the resin-rich areas (not shown in fig. 11) were assigned neat resin properties, as listed in Table 1.

The $\mathrm{u}$ - and v-displacements at the nodes at the thick end of the model were prescribed zero values to simulate clamped-end conditions. An axial tension load of $35.6 \mathrm{kN}$ (8000 lbs.) was applied at the thin end $(X=337 \mathrm{~mm})$ as a concentrated load (See fig. 7$)$.

Transverse bending was produced by a point load of $\mathrm{V}=-4.45 \mathrm{kN}$ $(-1000 \mathrm{lbs}$.) applied at the thin end of the model, corresponding to the pivot point in the ATB load frame. To determine the effect of the bending load on each surface, the bending 
load was applied first in the negative $Y$-direction, and then in the positive Y-direction.

\section{Computational Methods}

The ABAQUS finite element code was used in the analysis. Because the flexbeam undergoes large deflections, the geometric nonlinear solution option was used. Also, as with the ATB load frame, the axial load in the model was able to rotate with the flexbeam as it deformed under the transverse load. The ABAQUS program was used to calculate displacements, and internal stresses and strains.

To study the effects of changes in the ply waviness, modifications were made to the original mesh. Using the PATRAN code, marcels 1,2, and 3 were modified several times to reduce the amount of waviness at each location and the resin-rich areas were removed. The new models were analyzed with the same loading and boundary conditions, and the results were compared.

\section{RESULTS AND DISCUSSION}

\section{Global Response Comparison}

Calculated values from the FE model for transverse displacements, $v$, at the flexbeam tip were compared to the test results to determine the accuracy of the FE model to reproduced the global behavior of the test specimens under the same loading conditions. Figure 12 compares the maximum surface strains vs. flexbeam tip displacement, as measured by gages 4 and 9 , in the static excursion tests, along with the calculated results from the ABAQUS FE model. The transverse displacement was varied while the axial load was held constant at $35.6 \mathrm{kN}$ (8000 lbs). The agreement is good throughout the range of tip-displacement, on both the tension and compression sides, although the calculated strains are slightly lower everywhere.

In fig. 13, measured surface strains from the ten strain-gage locations are compared to the ABAQUS calculated strains along the flexbeam length. The calculated values are shown in the solid circles and test results are shown for a severely marcelled specimen (specimen 2, open circles) and a moderately marcelled specimen (specimen 4, open squares). The results shown are at $P=35.6 \mathrm{kN}$ (8000 lbs.) and $\delta=27.9 \mathrm{~mm}(1.1 \mathrm{inch})$. Gages 1-5 were on the tension surface, and gages 6-10 were on the compression surface, as shown in the inset in fig. 13. The agreement is reasonable for gages $1,2,4$, and 5 on the tension surface. However, at the gage 3 location ( $X=85.8 \mathrm{~mm}, 3.38$ in.), the calculated strain is much higher than the measured strain from specimen 4 . The FE model duplicated specimen 2, which has a large marcelled area near the surface at gage 3 , which is not present in specimen 4 . However, the data point for specimen 2 at the gage 3 location is shown with an upward arrow to indicate that the strain reading had exceeded the limit of the gage $(.012 \mathrm{~mm} / \mathrm{mm})$. As the figure shows, the surface strains varied for the different specimens. Along the compression surface, $F E$ results are not as accurate near $X=0$, but are reasonably close at gage locations 8-10 and follow the trend of the data. Based on these results, the FE model appears to duplicate well the global response of the test specimens under loading in the ATB. 


\section{Static Test Results}

During the static excursion tests of specimens 1,2 , and 3 , all of which had severe waviness, some delamination damage occurred. This was first noticed as faint "clicking" noises as the transverse bending loads were applied. A visual check was made before increasing the load each time. In specimen 1, a crack formed first at the location corresponding to marcel 1 in fig. 11, at a transverse displacement of $\delta=12.7 \mathrm{~mm}(0.5 \mathrm{in})$. Several small delaminations were observed through-the-thickness at the same location. As static loading continued, more delaminations developed at other interfaces through-thethickness. Figure 14 shows a photo of the coated surface with the delamination damage. Along with the internal delamination damage, there was significant surface ply splitting in the surface fabric above the surface marcel. Because of the large amount of delamination sustained in the static testing, specimen 1 was not fatigue tested. Specimens 2 and 3 each developed a small delamination at marcel 1 also, approximately one quarter of the thickness from the surface, when the transverse displacement reached $\delta=20.3 \mathrm{~mm}(0.8 \mathrm{in}$.). These specimens were fatigue tested with the initial delamination damage. Specimens 4-6 had no apparent damage after static testing to a maximum transverse displacement of $\delta=27.9 \mathrm{~mm}$ ( 1.1 inch).

\section{Fatigue Test Results}

The specimens were visually monitored throughout the fatigue loading cycle. For specimens 2 and 3, which had a large marcel at the location "marcel 1" (see fig. 11), damage began at that location, as a crack through the wavy area, followed by a delamination at the interface under the marcel. This initial crack formed almost immediately, i. e., at less than $\mathrm{N}=50$ cycles. As cycling continued, delaminations formed at neighboring interfaces, through the wavy areas. These delaminations grew in both directions with further loading. The internal delamination damage was always accompanied by splitting and peeling of the surface fabric ply at the location over the surface marcel. Continued fatigue loading caused delaminations to form and grow at interfaces in the wavy center-ply-groups, near the thick end of the flexbeam. Figure 15 shows the delamination damage in specimens 2 and 3.

The first observed damage in specimens 4-6, which initially did not appear to have any marcels near the surfaces, appeared as a crack near the surface, similar to the initial damage in specimens 2 and 3 . These cracks occurred soon after cyclic loading began, at approximately $\mathrm{N}=400$ cycles. Very small delaminations were observed at the cracks, although, unlike specimens 2 and 3 , these delaminations grew very slowly and stably with continued loading. In specimens 4 and 6, delaminations first grew toward the thick end of the laminate, and then grew from the crack toward the thin end. In specimen 5, the delamination grew only toward the thick end. The fatigue loading was continued for these laminates until a delamination had grown from the onset location to the grip at the fixed (thick) end. This condition was considered final failure. Figure 16 shows the final failure of specimens 4 and 5 . After testing, the original photographs of specimens 4-6 were reexamined. Surface marcels were found at the locations where the initial cracks formed, as in specimens 2 and 3, although these marcels were of much smaller magnitude.

Figure 17 compares the number of cycles to final delamination failure for specimens 2-6, with the results from ref. 2, for identical specimens, but without any ply waviness. The solid circular symbols in fig. 17 show the number of cycles to develop the initial crack through the wavy areas and the open circular symbols indicate the final failure. Even though the flexbeams in this study were tested at lower maximum strain levels than the flexbeams without waviness in ref. 2, failures occurred at significantly shorter lives. The fatigue lives of 
specimens 2 and 3, with large amplitude marcels near the surface, were 1 to 2 orders of magnitude shorter than specimens 4-6, with smaller amplitude surface marcels.

\section{Analytical Results}

Ply waviness was characterized in this paper by the aspect ratio of the marcel, defined as the half-amplitude, $\alpha$, divided by the width of the period, $L$ (see the inset in fig. 18). In the FE model, the highest aspect ratios were found to be in the center ply-drop groups toward the thick-end of the flexbeam and in the isolated marcels near the surfaces. All of those marcels had an $\alpha / L$ of 0.055 to 0.085 . The aspect ratios of the marcels in the center plies decreased gradually along the length of the flexbeam.

Results of the FE model analysis were used to determine the peak interlaminar normal stresses, $\sigma_{n}$, in the model. The $\sigma_{n}$ stresses reported are with reference to the element local (n-t) coordinate system, rather than the global coordinate system (fig. 10). Several studies have shown that delamination failure in composites with similar geometry is predominantly due to opening mode failure (normal to the ply direction) $[2,4,5,6]$, with a much smaller contribution from the interlaminar shear mode. In this study, therefore, delamination was also assumed to be controlled by the interlaminar tension, and only the interlaminar normal stresses were considered. Peak $\sigma_{n}$ stresses occurred in the model at marcel 1 , and another area of high $\sigma_{n}$ stresses existed at marcel 3 (fig. 11). When the transverse load direction was reversed ( $V=4.45 \mathrm{kN}, 1000 \mathrm{lbs}$ ), peak stresses occurred at marcel 2. In all cases, the peak stresses occurred at the most interior point of the marcel.

In order to determine the effect of marcel location on interlaminar normal stresses, the model was inspected to find marcels of the same aspect ratio, but at different $X$ - or $Y$ locations. Figure 18 shows the effect of varying the $X$-location of a marcel, while keeping the aspect ratio and distance from the surface constant. The figure compares calculated interlaminar normal stresses, at marcelled areas of the model with aspect ratios of either 0.085 or 0.045 , at approximately the same distance from the surface, but different $X$ locations. As the figure shows, for either aspect ratio, the stresses increase as the location of the marcel moves from the thick end toward the thin region.

In fig. 19, the effect of the location of the marcel through-the-thickness is shown. For this case, stresses at different locations through-the-thickness are plotted for marcels with aspect ratios of 0.085 and 0.045 , the same distances along the taper. The stresses are plotted as a function of the distance from the upper surface, $\bar{y}$, divided by the section half-thickness, $t(x)$. As fig. 19 shows, stresses decrease sharply for both aspect ratios, as the marcel location moves from the surface toward the midplane of the flexbeam. Exponential curves were fitted to the data in fig. 19.

To determine the effect of the marcel aspect ratio, the aspect ratios of marcels 1-3 in the original FE model were modified and the analyses were repeated. The aspect ratio of marcel 1 was reduced from the original 0.085 , to $0.055,0.034$, and 0.025 . Marcel 2 was modified from the original aspect ratio of 0.05 to $0.028,0.02$, and then 0.014 . The aspect ratio of marcel 3 was reduced from 0.085 to $0.08,0.07,0.06$, and 0.03 . Figure 20 shows a comparison of the $\sigma_{n}$ stresses at locations marcel 1,2, and 3, as the aspect ratio was varied at each location. The peak interlaminar normal stresses increase exponentially as the aspect ratio increases. Again, the stresses are always highest for marcel 1, the marcel furthest from the fixed end. The curves for marcels 2 and 3 , which are near the thick end, and at similar Xlocations, appear to cross at an aspect ratio of about 0.03 , but at higher aspect ratios, marcel 3, nearest the thick end, is the lower bound of the stresses. 
The test results from fig. 17 were used with the calculated curves from fig. 20 to correlate the interlaminar normal stresses with the fatigue lives of the flexbeam test specimens. For each of the tested specimens, the aspect ratio was measured at the marcel where the delamination failure initiated. The corresponding interlaminar stress from the FE analysis was determined from the appropriate curve in fig. 20 . The curve for marcel 1 was used to determine the stresses for specimens 2 and 3 , since for those specimens, delamination damage initiated there. For specimens 4-6, the curve for marcel 2 (at $X=37.3 \mathrm{~mm}$ ) in fig. 20 was used, since the $X$-location was closest to the actual location of the marcels where failure began. For specimen 4, damage initiated at a small marcel at $X=50.8 \mathrm{~mm}$, and for specimen 5 and 6 , at $X=48.26 \mathrm{~mm}$. The resulting $\sigma_{\mathrm{n}}$ values were plotted against the number of loading cycles to failure for the test specimens, in fig. 21. As the interlaminar normal stresses decrease, the fatigue life increases. This figure also shows the data from the flexbeams without waviness from ref. 2 . Finite element results from ref. 2 showed that the maximum value of $\sigma_{\mathrm{n}}$ under combined tension-bending loading was $12.5 \mathrm{MPa}$. Based on fig. $21, \sigma_{n}=13.0 \mathrm{MPa}$ was chosen as the limit below which delamination failure will not occur at less than $\mathrm{N}=200,000$ cycles.

In fig. 22, this lower limit is plotted with the curves and data from fig. 20 . The intersections of the curves show the maximum allowable $\alpha / L$ values for the corresponding $X$-locations in the flexbeam. Using the assumed lower limit, no marcel would be allowable at $X=76.7$. At the $X=37.3$ and $X=27.4$ locations, marcels with aspect ratios of no more than 0.015 and 0.004 , respectively, would be acceptable.

\section{Discussion}

Using this technique of combining test data with FE model results, a lower limit of interlaminar normal stress can be chosen for a desired fatigue life. That normal stress can then be used, as in fig. 22, to determine the maximum allowable aspect ratio at various locations in the flexbeam.

The technique described above could be used as a first attempt at determining whether or not a given flexbeam should be used or discarded. However, the method has several limitations: e. g., an unlimited number of wavy ply configurations are possible, but it is not practical to model each case to determine the effect on the interlaminar stresses. Furthermore, varying the mesh size in the FE model may change the calculated stresses significantly. A mesh refinement study is required to verify this. A more complete picture of the delamination process in these flexbeams may be provided by an energy-based analysis, such as that used in refs. 1,2, and 4, in which simulated delamination growth is modeled at various locations and the associated strain energy release rates are calculated. However, considering the discussion in fig. 17 and the considerably poorer performance of these flexbeams with marcels under the fatigue loading, the effort involved in such an analysis may not be justified.

\section{CONCLUDING REMARKS}

The effect of wavy plies on the durability of tapered laminated composite flexbeams was studied, for use in developing accept/reject criteria for these flexbeams. Tests were conducted on $25.4 \mathrm{~mm}$ wide coupon specimens, which were cut from a full-size flexbeam of S2/E7T1 glass/epoxy. All of the specimens had significant ply waviness through the center of the flexbeam and isolated areas with varying amounts of waviness at locations near the surfaces. The specimens were tested under combined axial tension and transverse bending loading. For all of the tested laminates, damage started as a crack 
through a marcel near the surface. As the loading continued, delaminations grew from the crack in both directions along the length away from the marcel and multiple new delaminations formed at neighboring interfaces. Even though the flexbeams in this study were tested at lower maximum strain levels than identical specimens without ply waviness from ref. 2, failures occurred at significantly shorter lives. Fatigue lives for the tested laminates ranged from $10^{3}$ to $10^{5}$ cycles. In contrast, identical flexbeams without marcels had fatigue lives of $10^{5}$ to $10^{6}$ cycles at slightly higher bending loads.

A parametric study was conducted to determine the effects of ply waviness along the taper and through-the-thickness. A (2-D) plane strain FE model was developed which modeled exactly the flexbeam lay-up and geometry of one of the test specimens, including the exact geometry of the wavy plies. The model was analyzed using the ABAQUS finite element program to determine the interlaminar normal stresses, $\sigma_{n}$. For marcels of the same aspect ratio, and at the same depth from the surface, $\sigma_{n}$ stresses increased with distance along the taper, from thick end to thin end. For marcels of the same aspect ratio, and at the same location along the taper, the $\sigma_{n}$ stresses decreased from the surface inward toward the flexbeam midplane. The model was modified several times by decreasing the amplitude of the waviness in three marcels near the surfaces and the analysis was repeated. It was found that the $\sigma_{n}$ stresses increased exponentially as the aspect ratio was increased in these surface marcels.

A technique was presented for determining the smallest acceptable marcel aspect ratio at various locations in the flexbeam. Test data were combined with calculated results for modeled marcels of different aspect ratios and at different locations, to determine a lower limit on the allowable interlaminar normal stresses. This limit was then related back to the calculated FE results to determine maximum allowable marcel aspect ratios to achieve a desired fatigue life.

\section{REFERENCES}

1. Li, J., and O'Brien, T. K., Ply Waviness Effects on the Pull-off Loads in Composite Hat Stringer Specimens," Proceedings of the 14th U.S. Army Symposium on Solid Mechanics, Myrtle Beach, SC, October 1996.

2. Murri, G. B., O'Brien, T. K., and Rousseau, C. Q., "Fatigue Life Methodology for Tapered Composite Flexbeam Laminates", Journal of the American Helicopter Society, Vol. 43, No. 2, April 1998, pp. 146-155.

3. Shivakumar, K. N., and Crews, J. H., Jr., "Bolt Clampup Relaxation in Graphite/Epoxy Laminate," Long Term Behavior of Composites, ASTM STP 813, T. K. O'Brien, Ed., American Society for Testing and Materials, Philadelphia, 1983, pp. 5-22.

4. Li, J., O'Brien, T. K., and Rousseau, C. Q., "Test and Analysis of Composite Hat Stringer Pull-off Test Specimens," Journal of the American Helicopter Society, Vol. 42, No. 4, October 1997, pp. 350-357. 
5. O'Brien, T. K., "Composite Interlaminar Shear Fracture Toughness, $\mathrm{G}_{\mathrm{Il}}$ : Shear Measurement of Sheer Myth?", Composite Materials: Fatigue and Fracture, Seventh Volume, ASTM STP 1330, 1998, pp. 3-18. Also available as NASA TM-110280, ARL TM-1312, February 1997.

6. Krueger, R., Cvitkovich, M. K., O'Brien, T. K., and Minguet, P. J., "Testing and Analysis of Composite Skin/Stringer Debonding Under Multi-Axial Loading", NASA TM-1999209097, ARL-TM-439, February 1999. 
Table 1. Material Properties

\begin{tabular}{lllll}
\hline Material & $\mathrm{E}_{11}, \mathrm{GPa}$ & $\mathrm{E}_{22}, \mathrm{GPa}$ & $\mathrm{G}_{12}, \mathrm{GPa}$ & $v_{12}$ \\
\hline S2/E7T1 tape & 47.6 & 12.6 & 4.81 & 0.28 \\
E-glass/E7T1-2 fabric & 25.3 & 24.1 & 4.56 & 0.153 \\
Steel & 201 & 201 & 77.3 & 0.30 \\
Neat resin & 4.10 & 4.10 & 1.54 & 0.33 \\
\hline
\end{tabular}

Table 2. Ply-Group Layups and Smeared Properties

\begin{tabular}{lcclll}
\hline Ply Group & Layup & $\mathrm{E}_{\mathrm{xx}}, \mathrm{GPa}$ & $\mathrm{E}_{\mathrm{yy}}, \mathrm{GPa}$ & $\mathrm{G}_{\mathrm{xy}}, \mathrm{GPa}$ & $v_{\mathrm{xy}}$ \\
\hline mid-plane & {$\left[0_{2} \overline{45}\right]_{\mathrm{s}}$} & 41.1 & 13.7 & 6.32 & 0.34 \\
Belt 1,2,4 & {$\left[0_{4}\right]$} & 47.6 & 12.6 & 4.81 & 0.28 \\
Belt 3 & {$\left[ \pm 45 / 0_{2}\right]$} & 31.6 & 15.6 & 9.19 & 0.33 \\
Fabric & woven \pm 45 & 25.3 & 24.1 & 4.56 & 0.153 \\
Dropped 1-4 & {$[ \pm 45]_{\mathrm{n}}$} & 14.8 & 14.8 & 13.3 & 0.33 \\
\hline
\end{tabular}

Table 3. Strain Gage Locations

Gage Number Distance from lower grip, mm (inches)

$\begin{array}{lll}1,6 & 12.7 & (0.5) \\ 2,7 & 53.3 & (2.1) \\ 3,8 & 82.6 & (3.25) \\ 4,9 & 98.5 & (3.88) \\ 5,10 & 160.0 & (6.3)\end{array}$




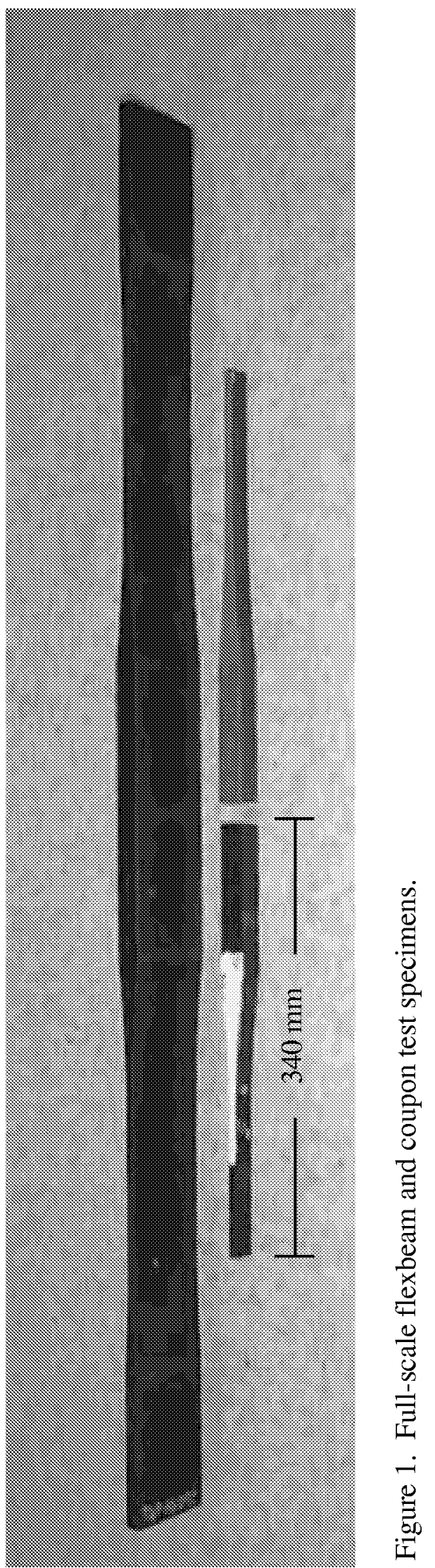




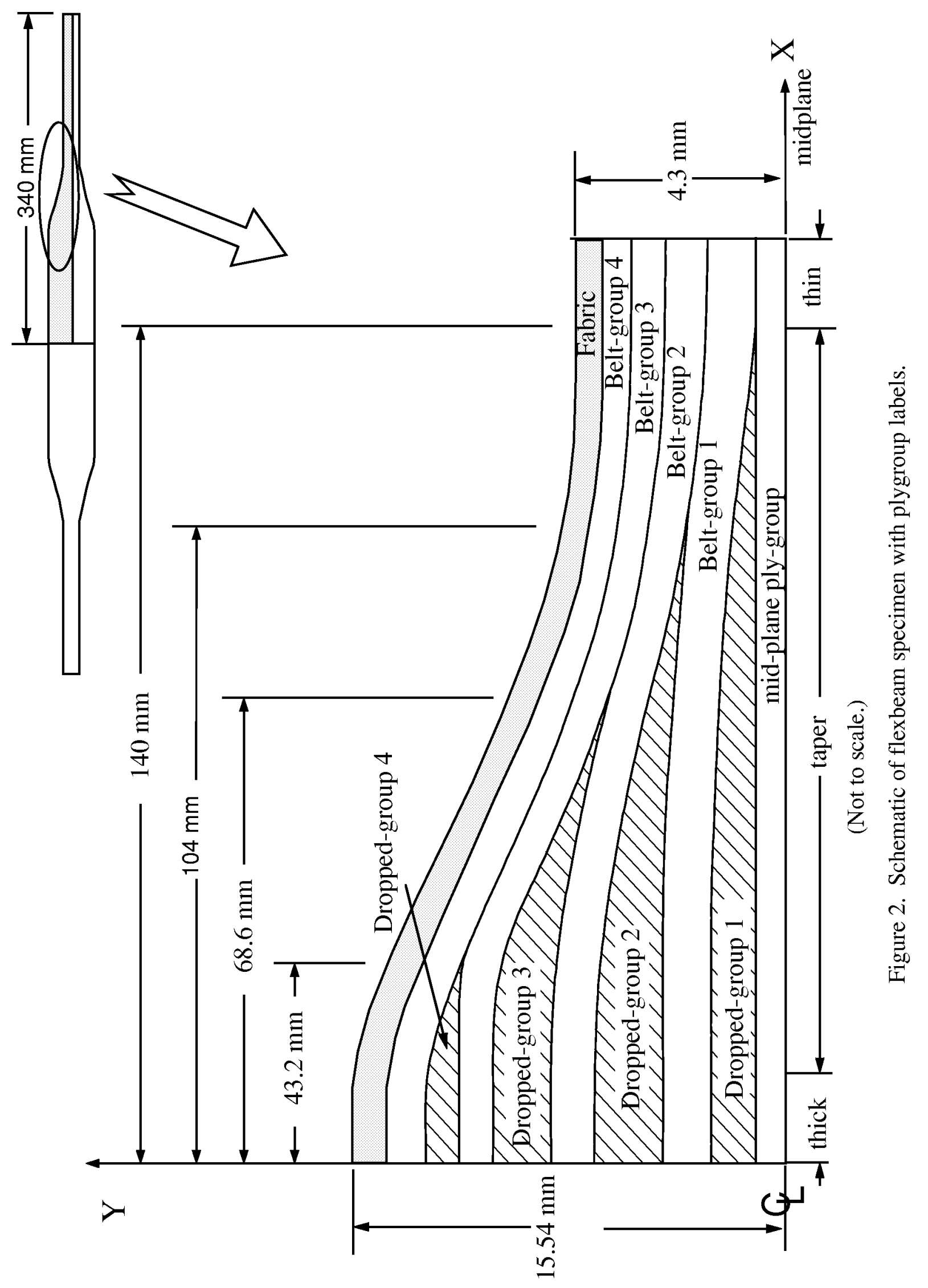




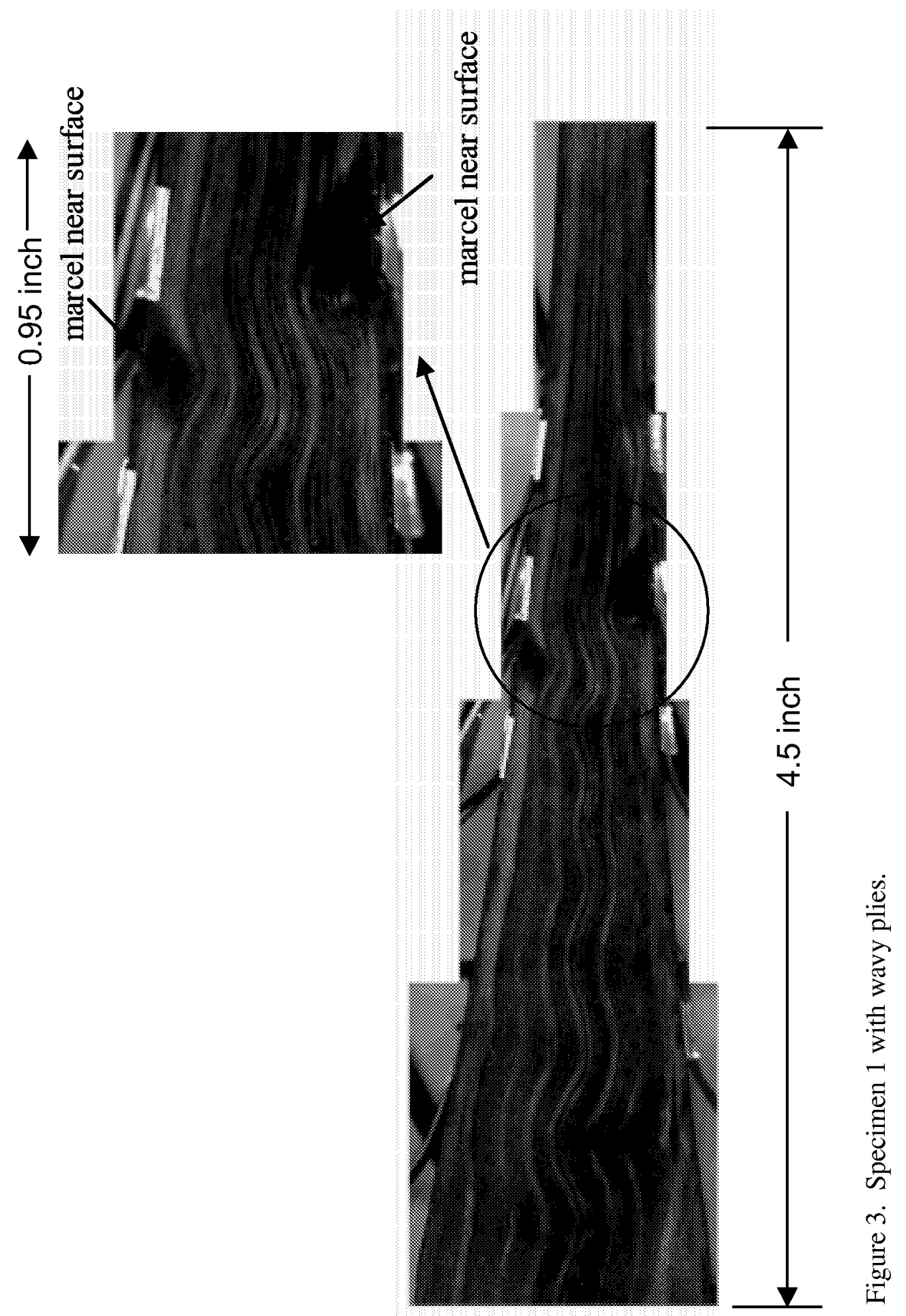




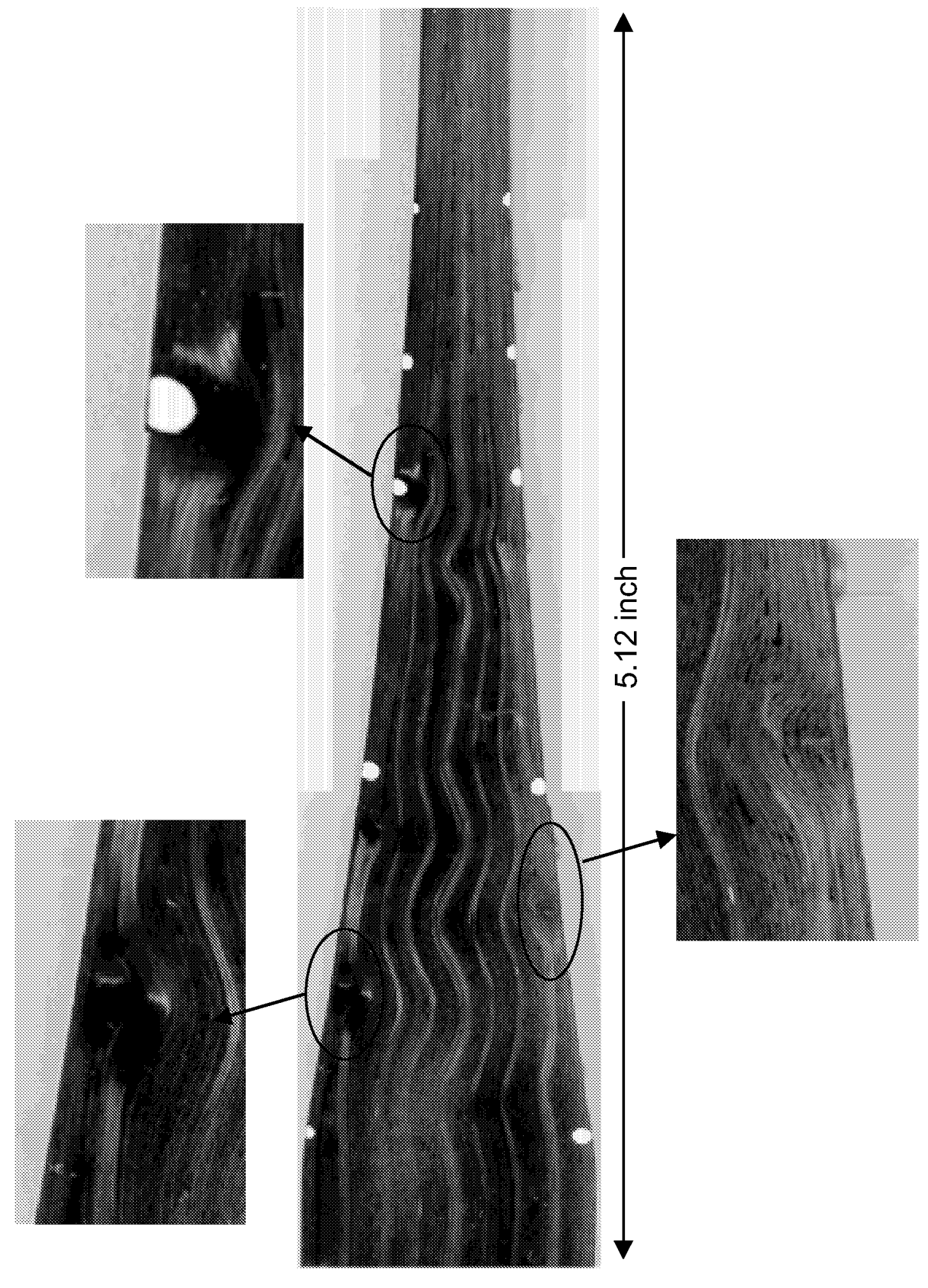

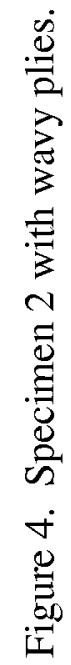




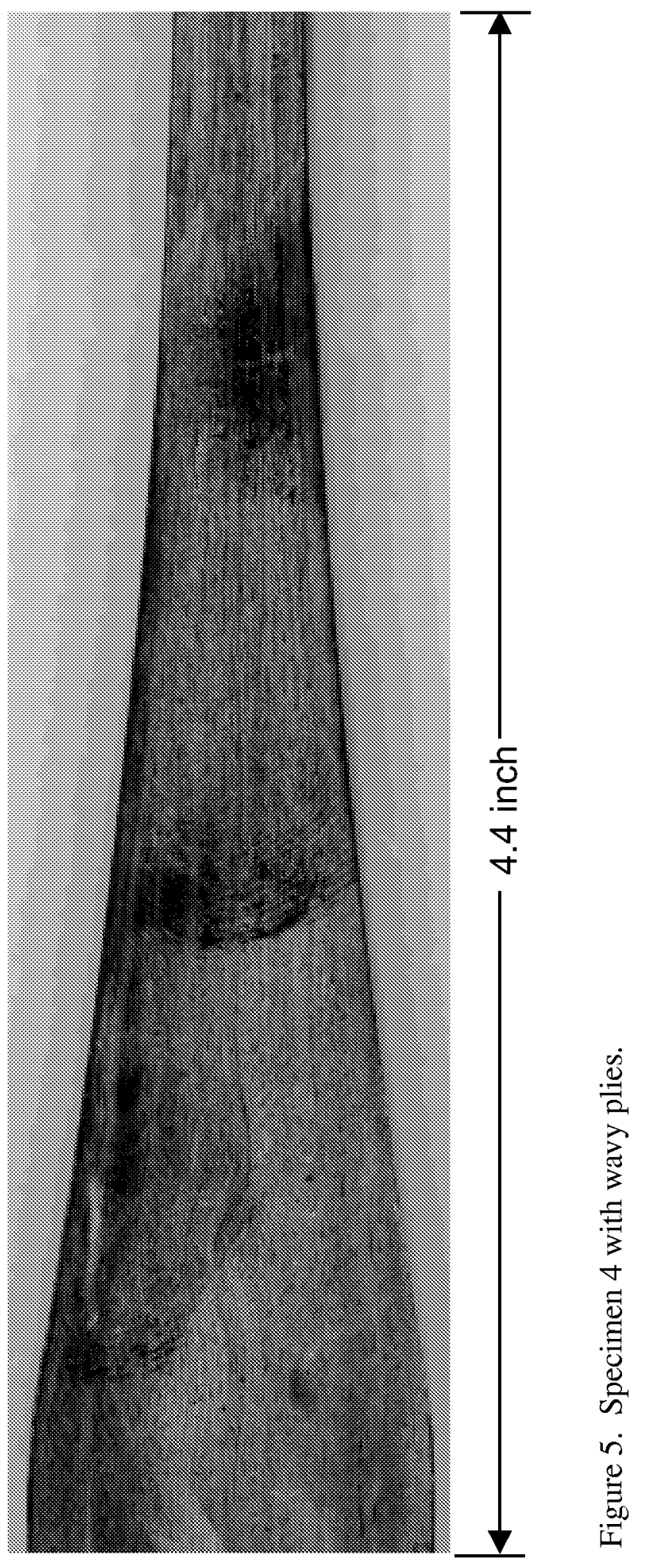




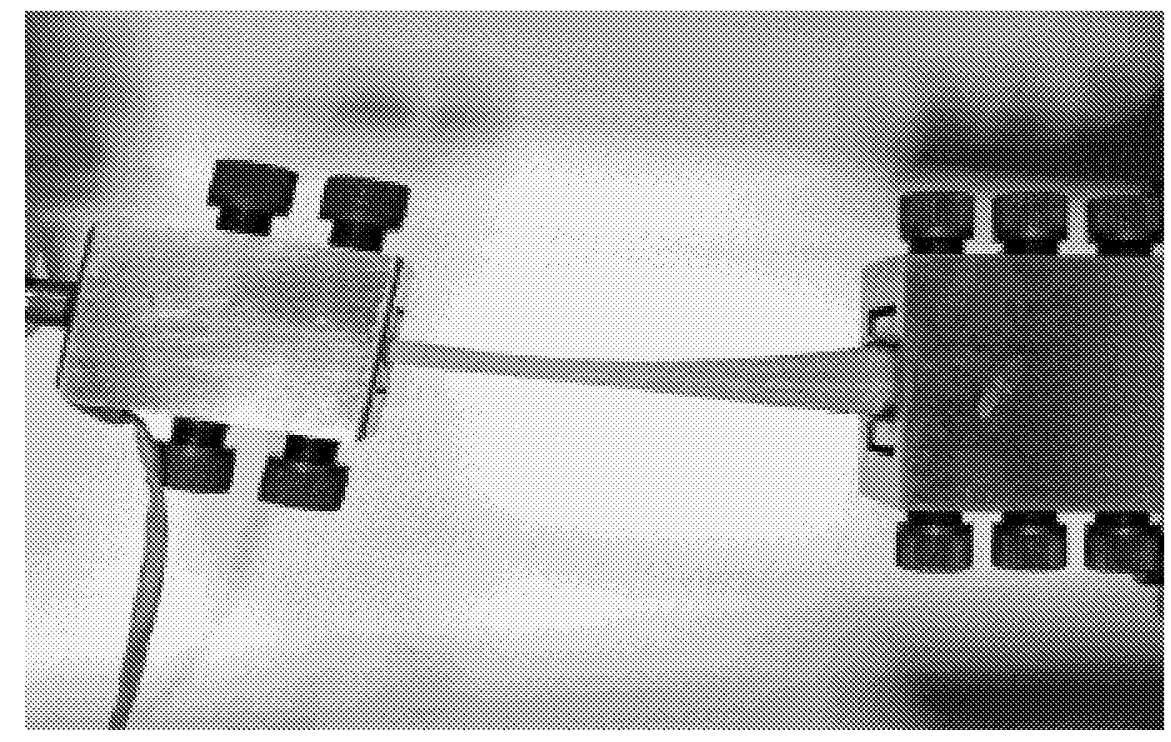

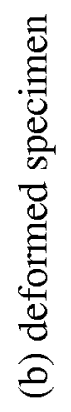

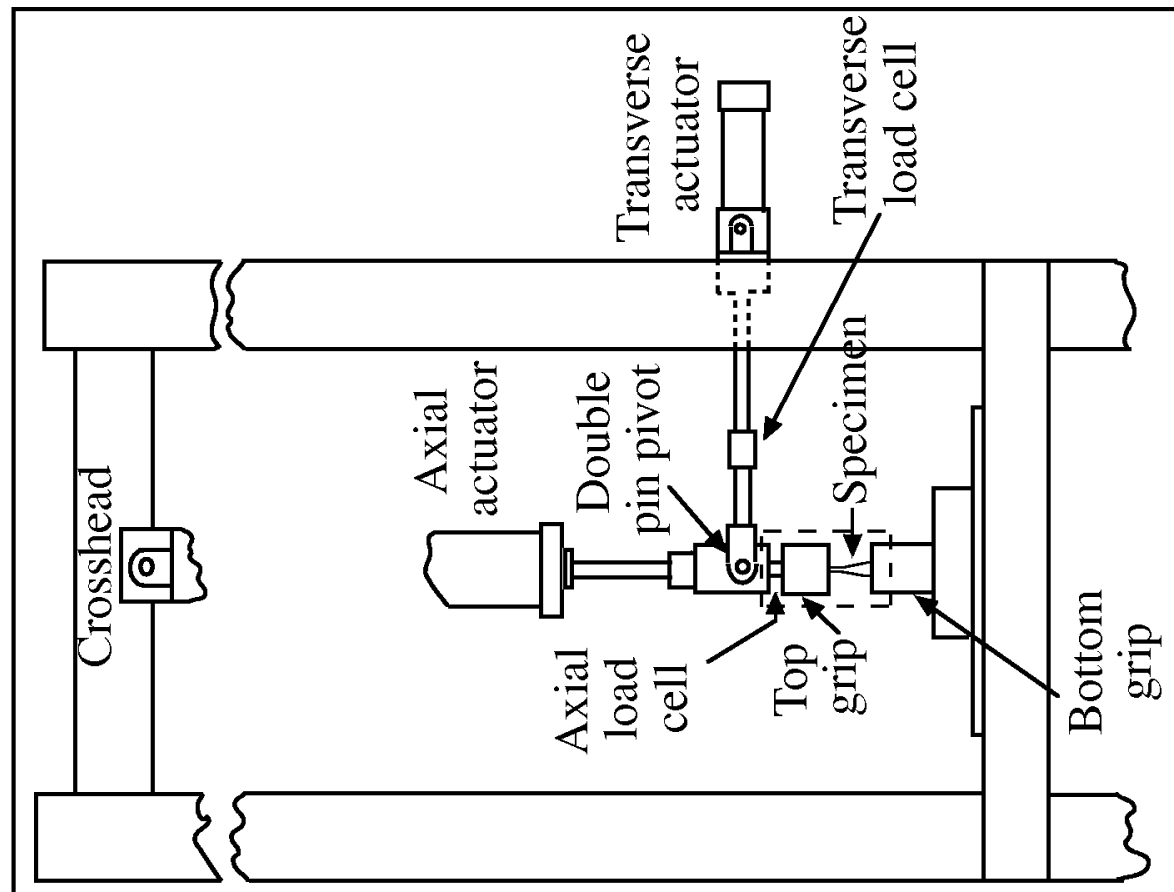

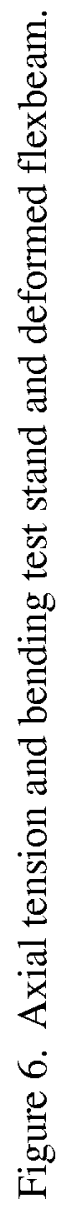




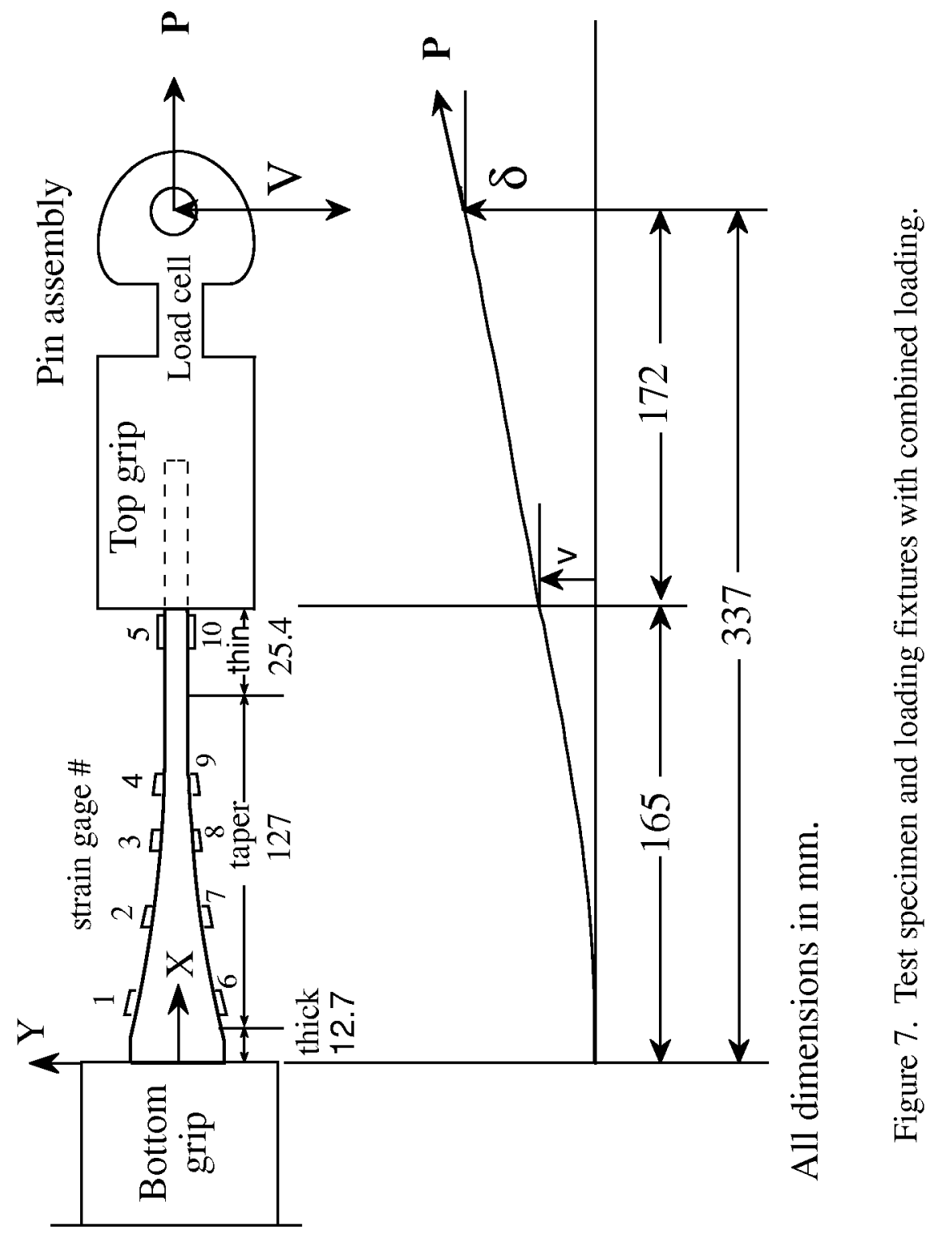




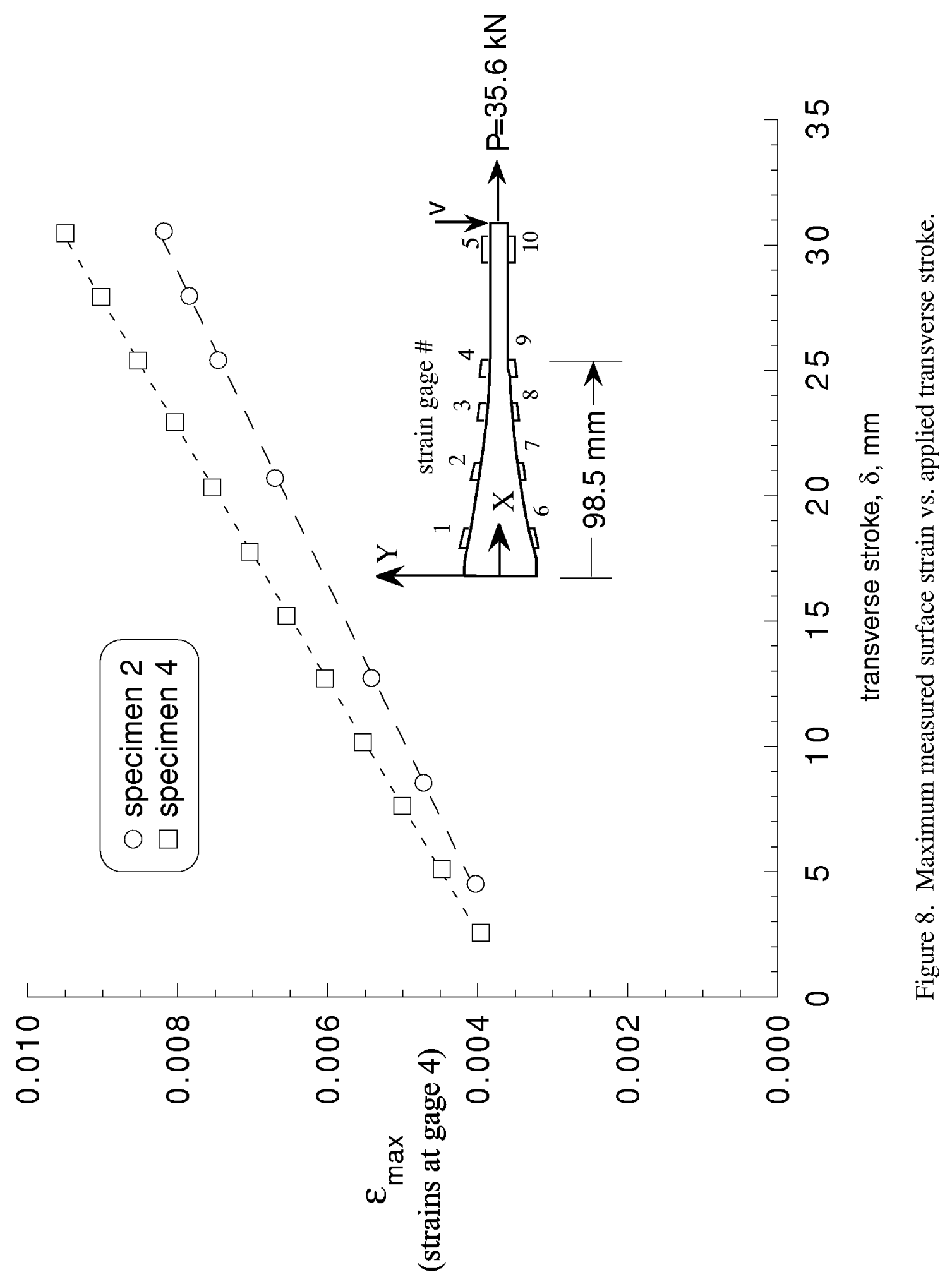




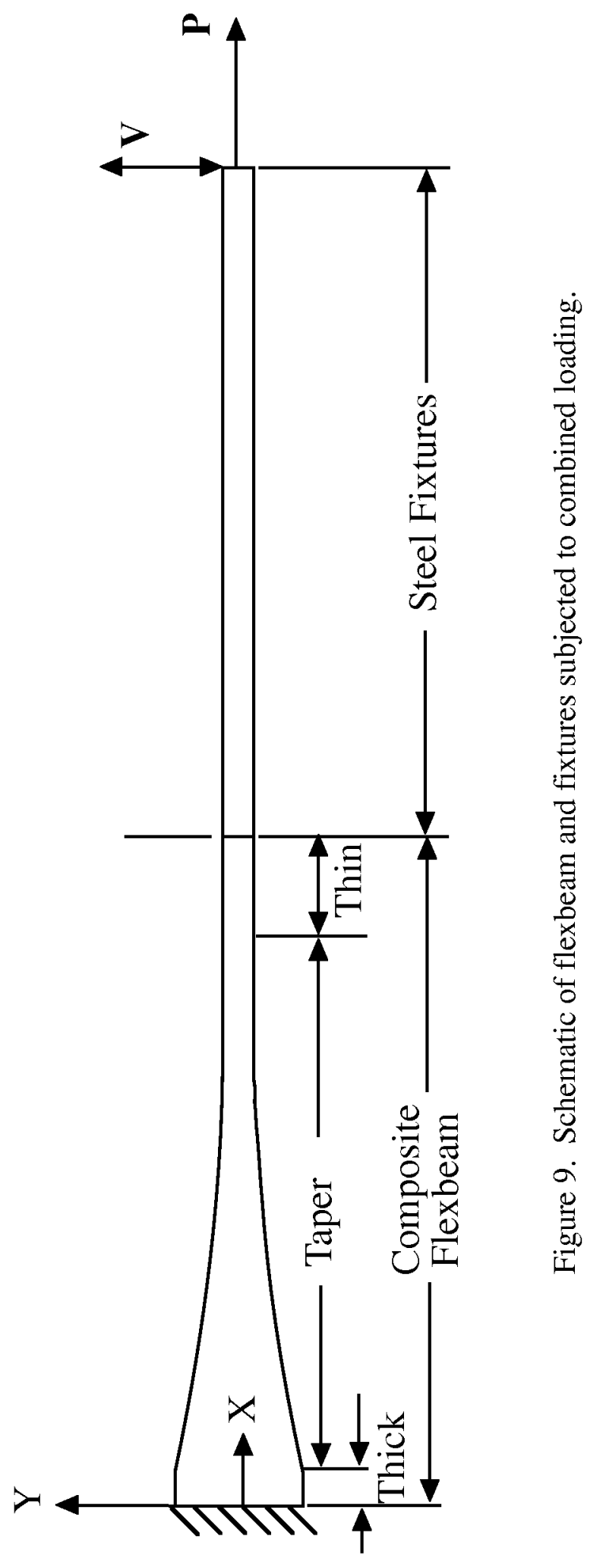



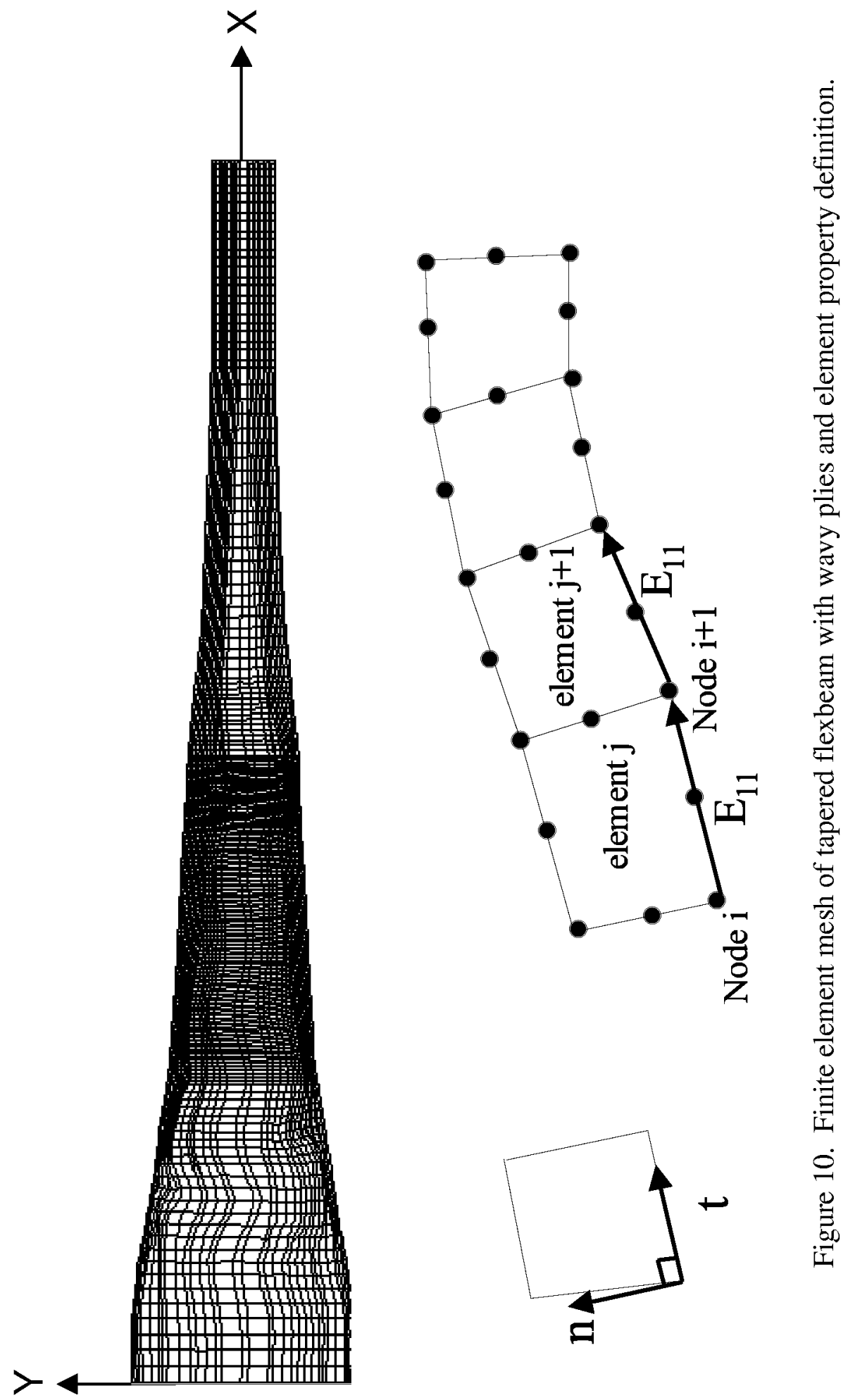


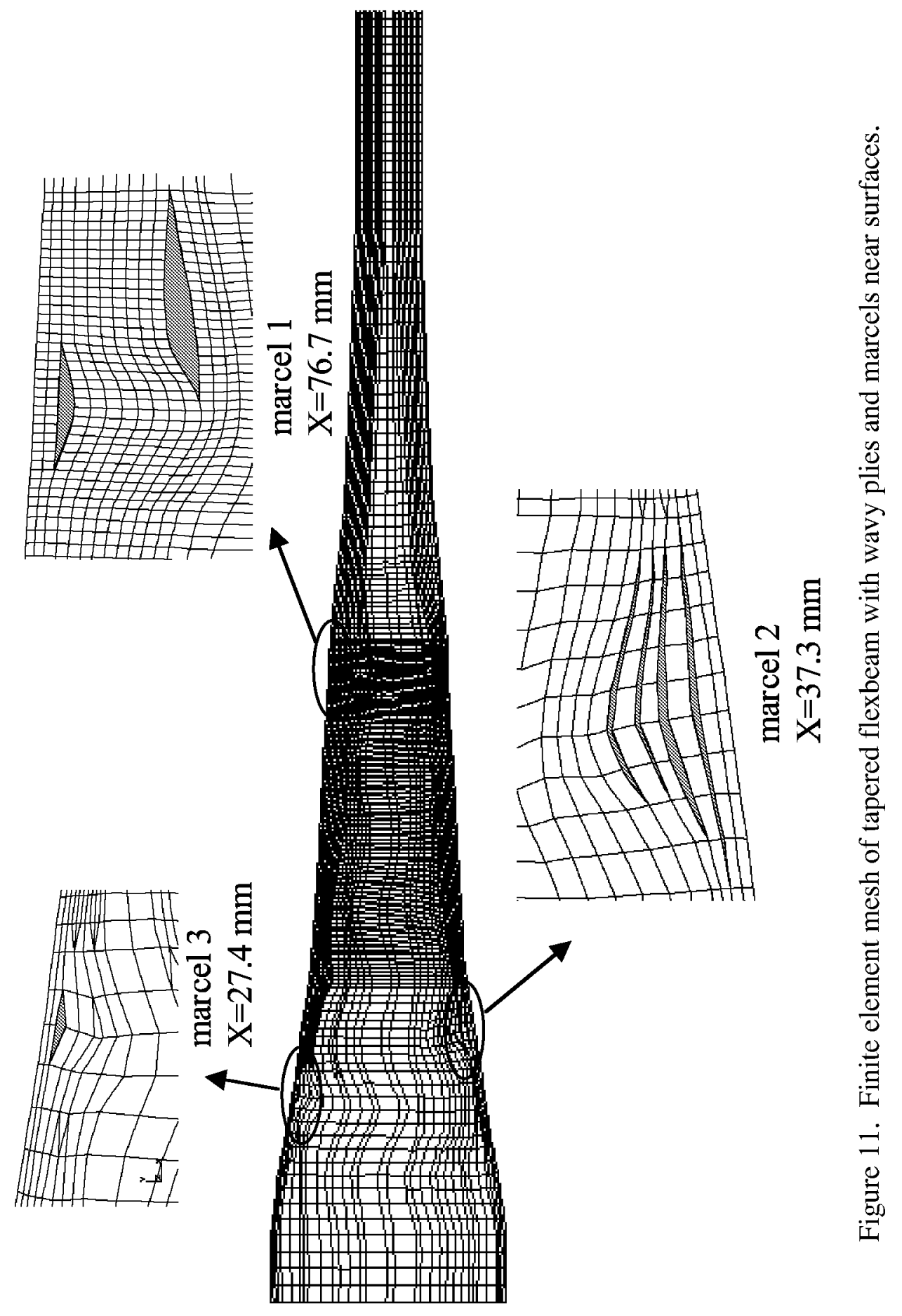




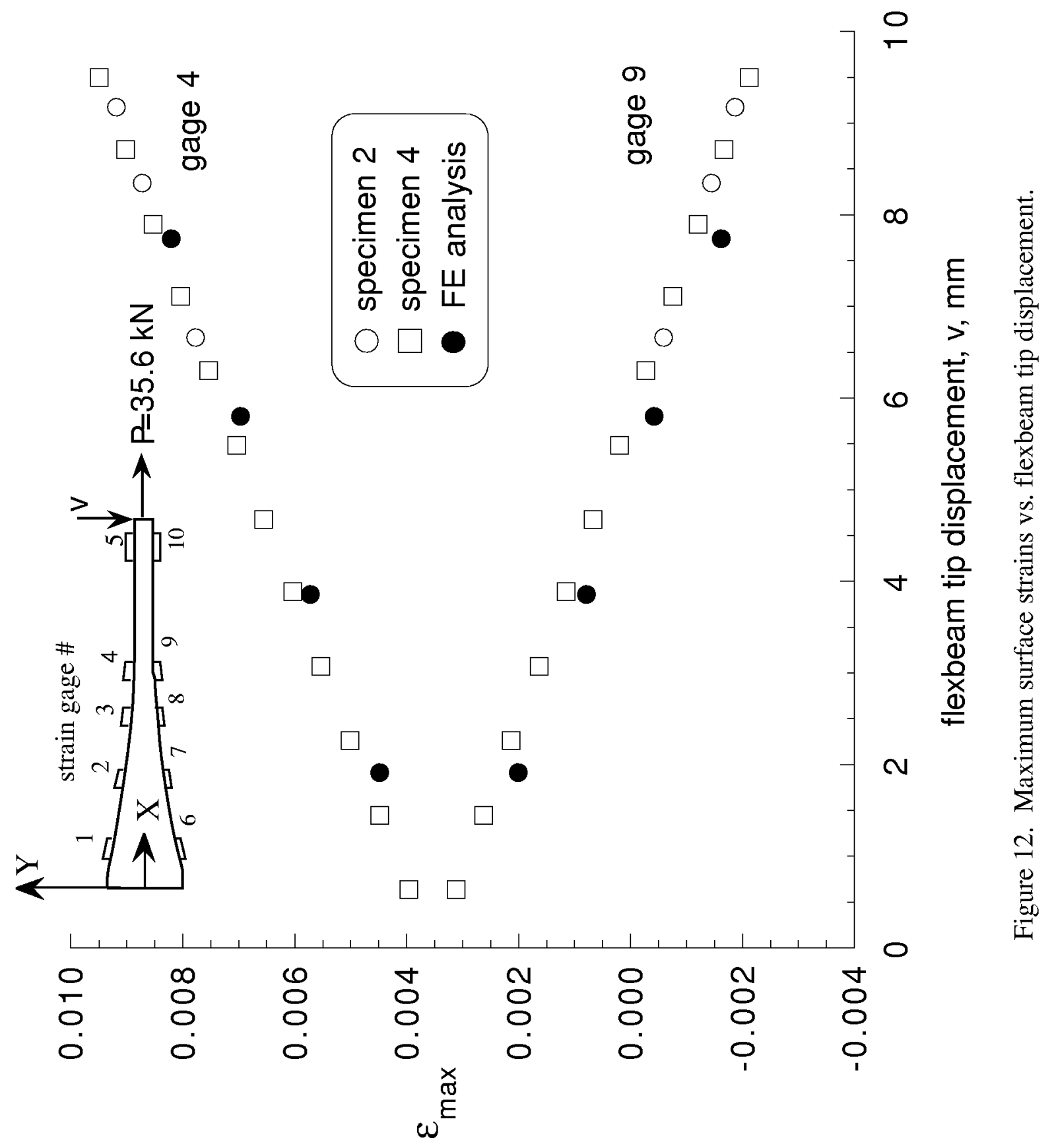



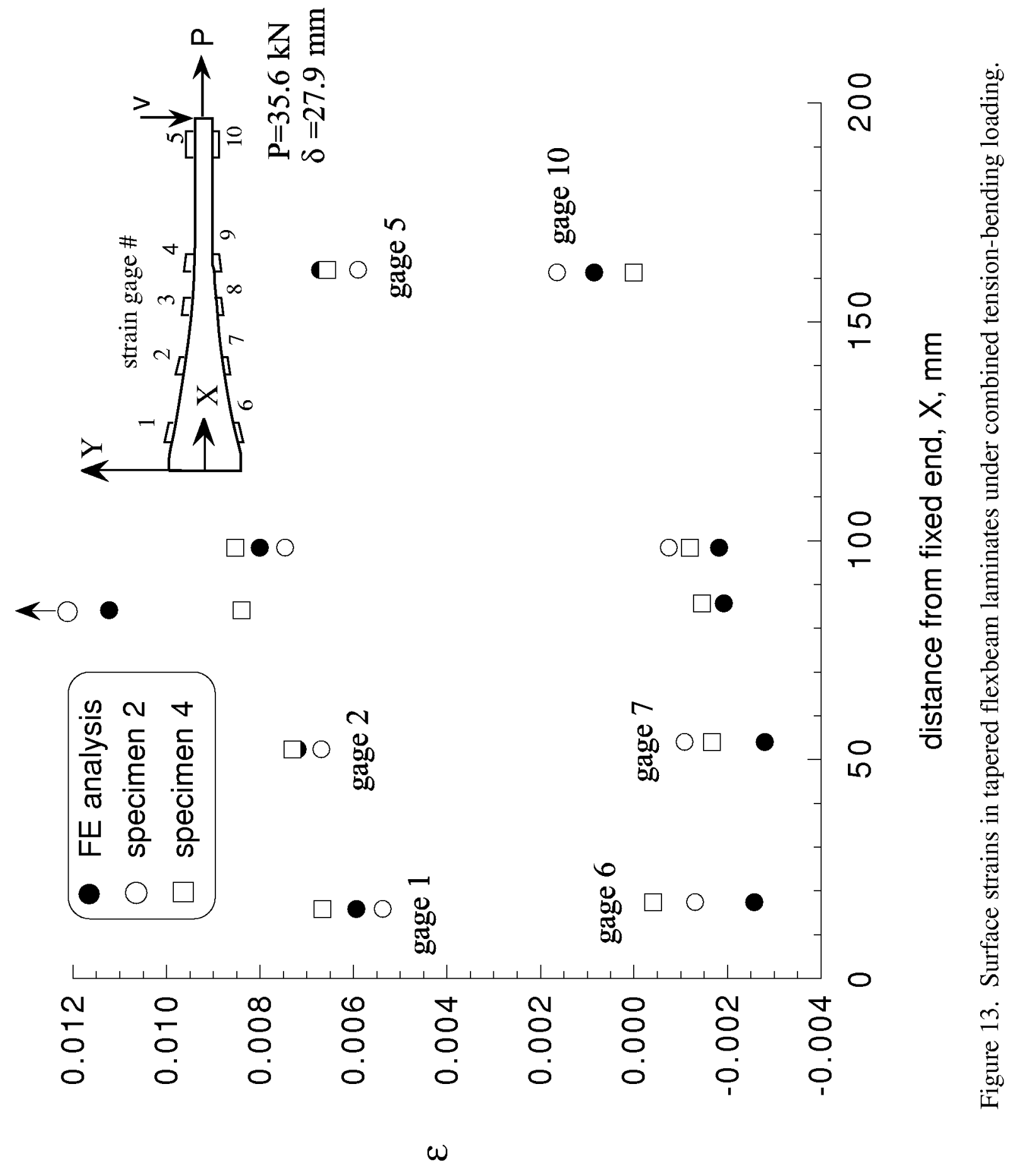


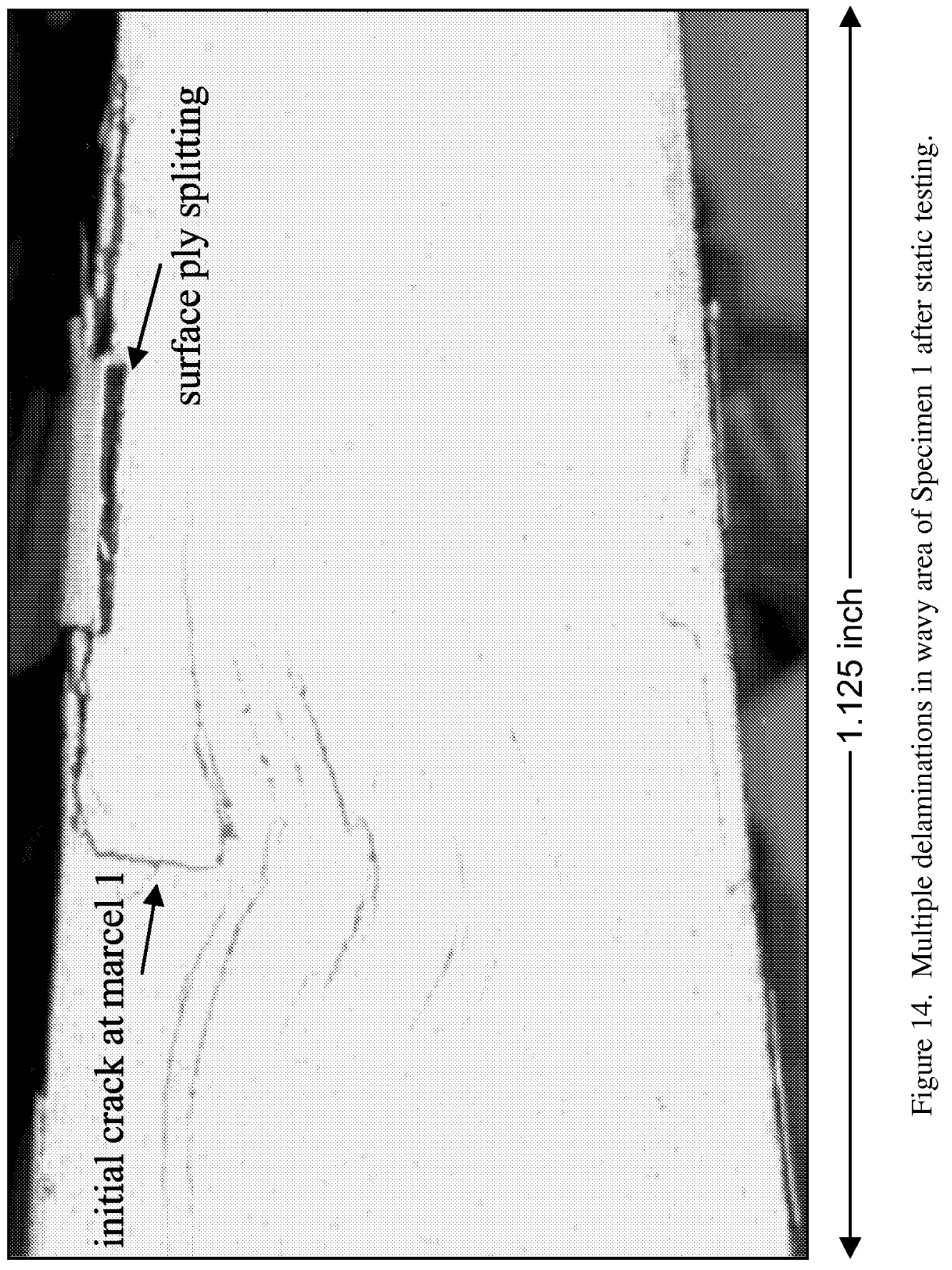




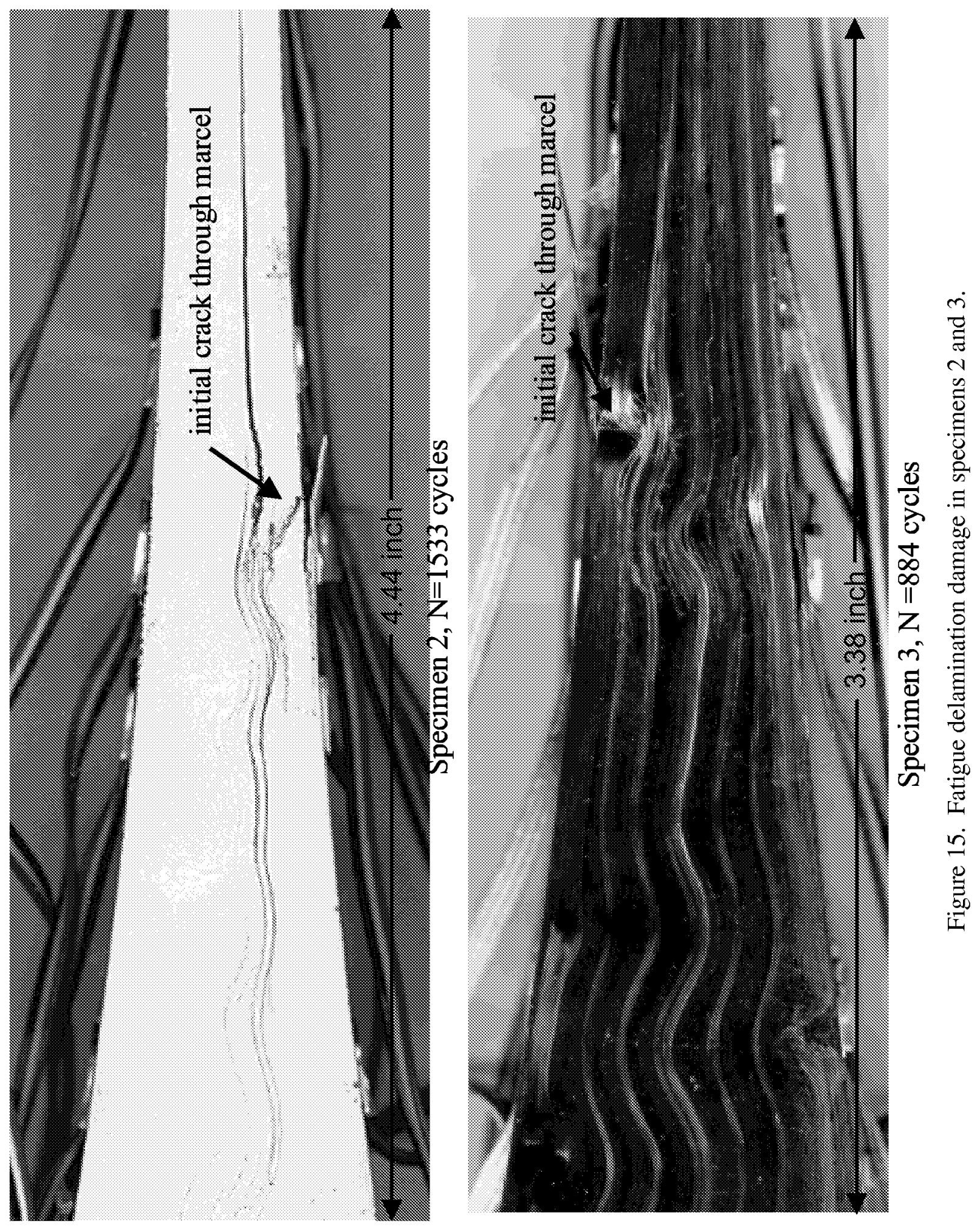




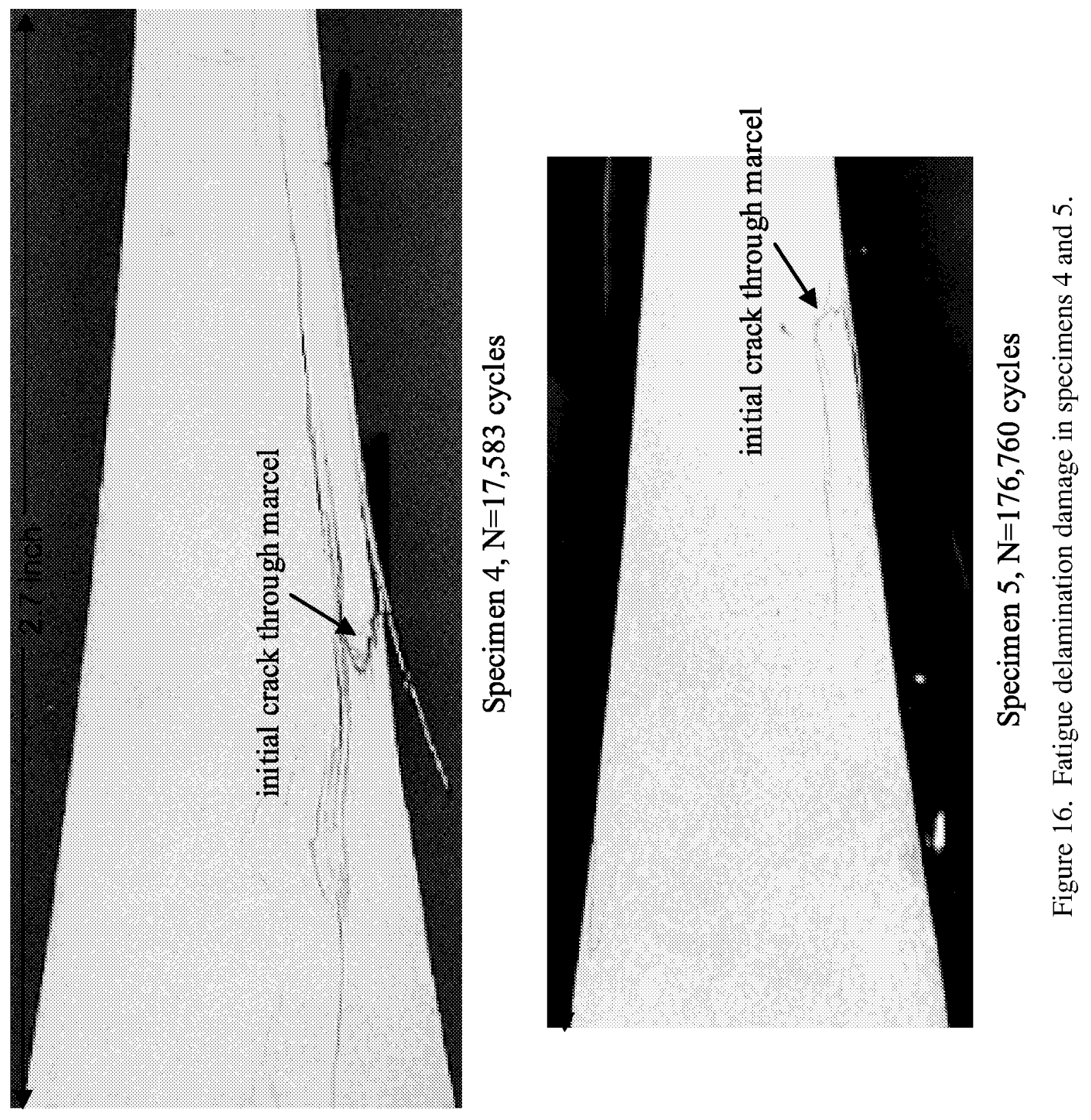




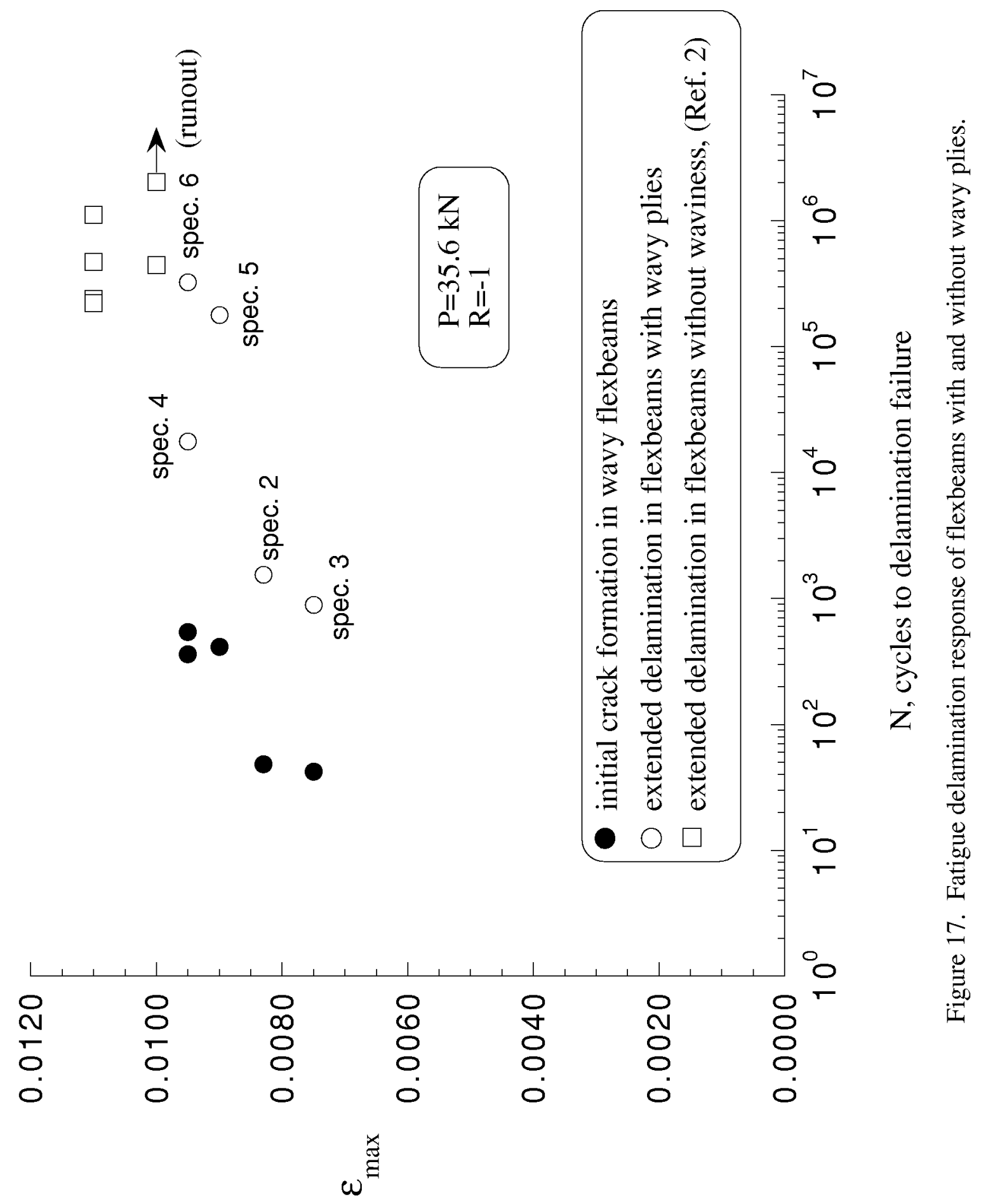




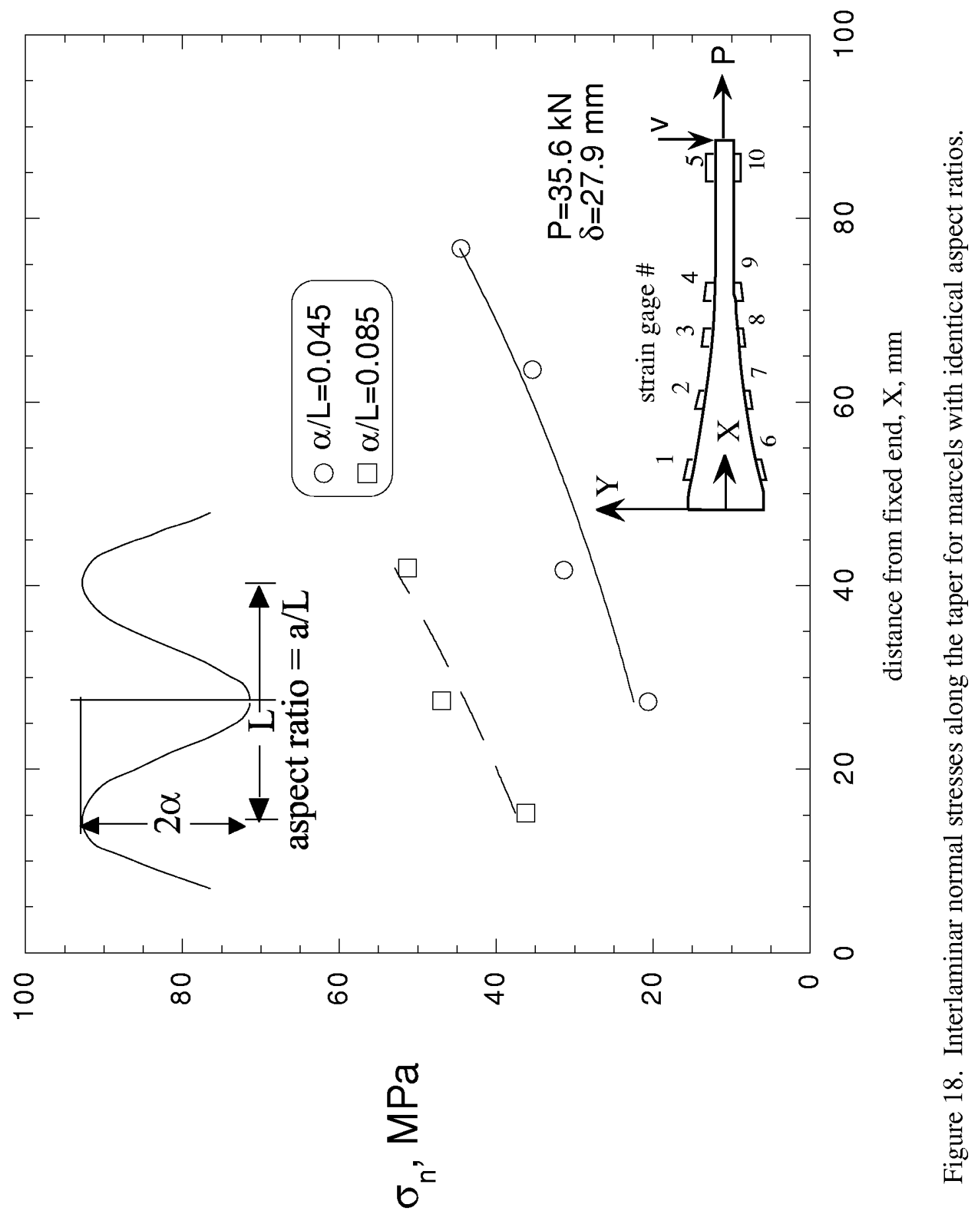




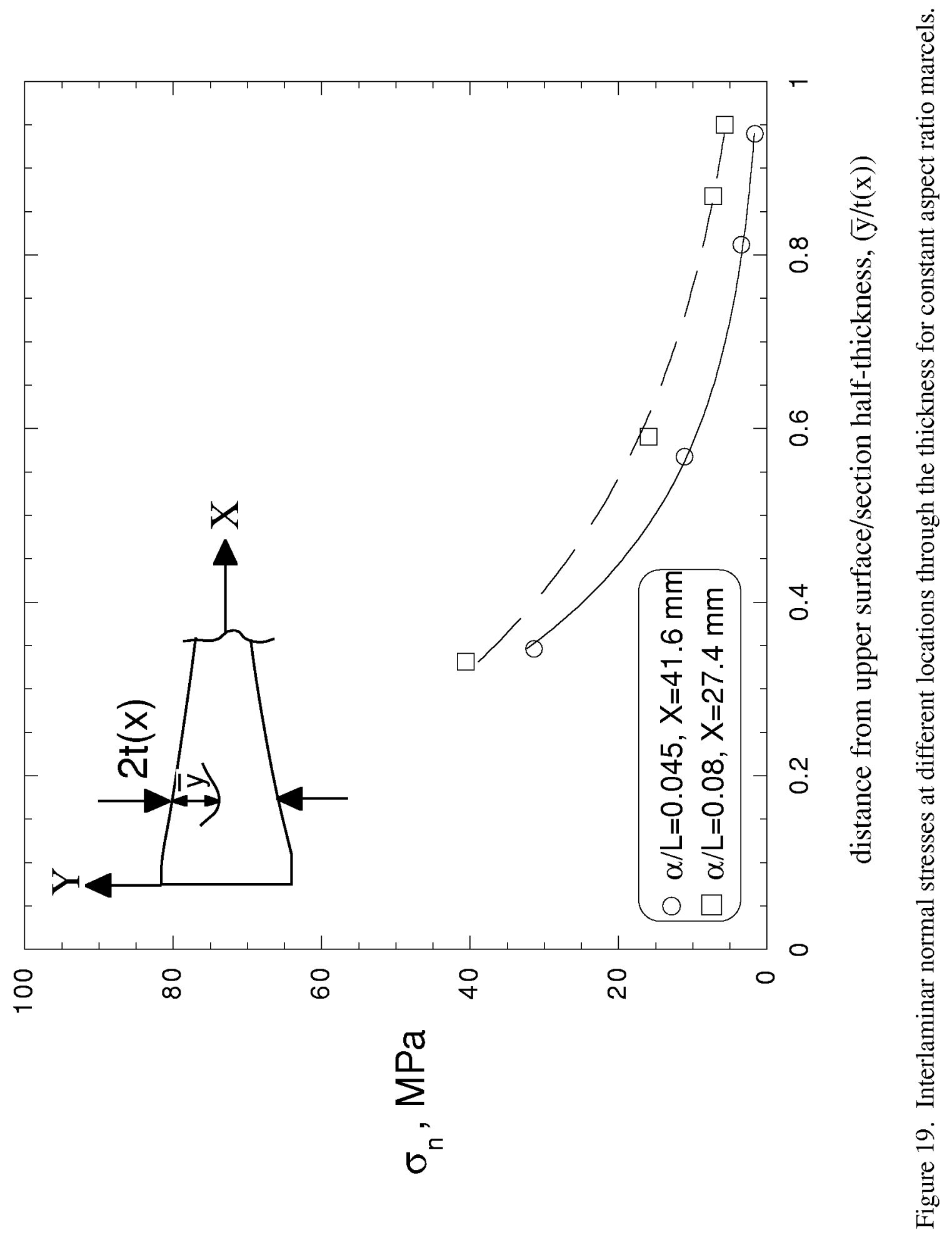




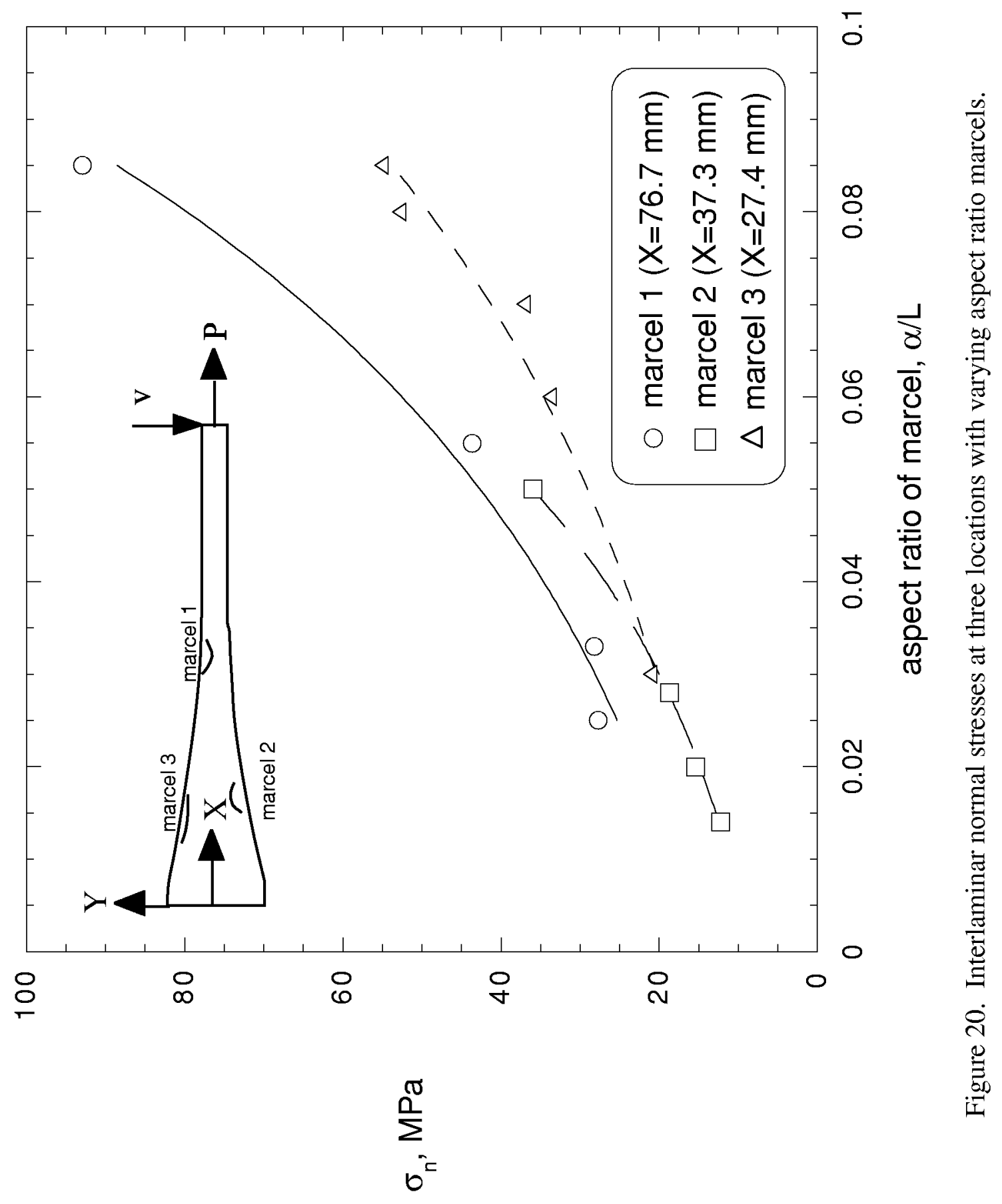




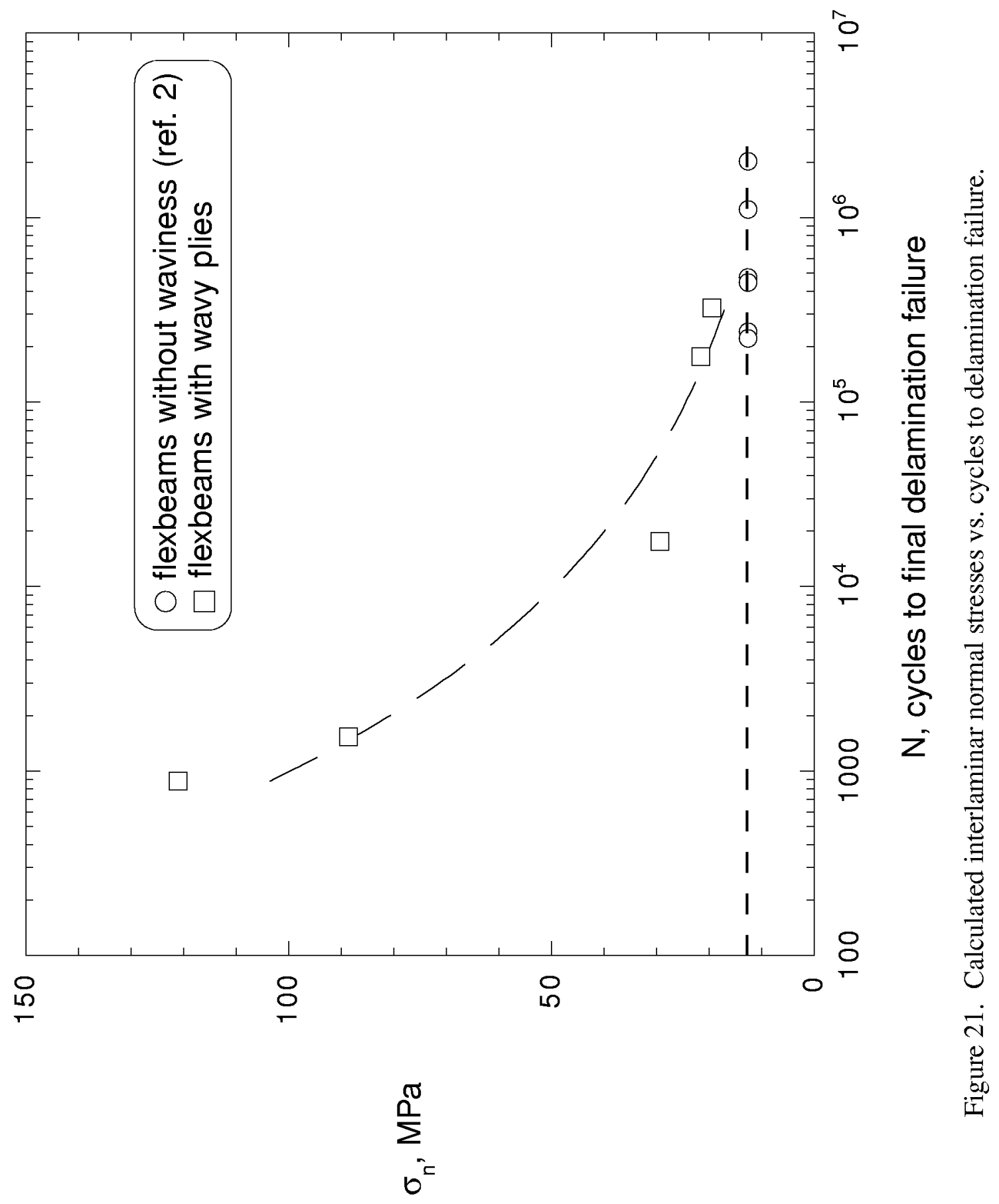




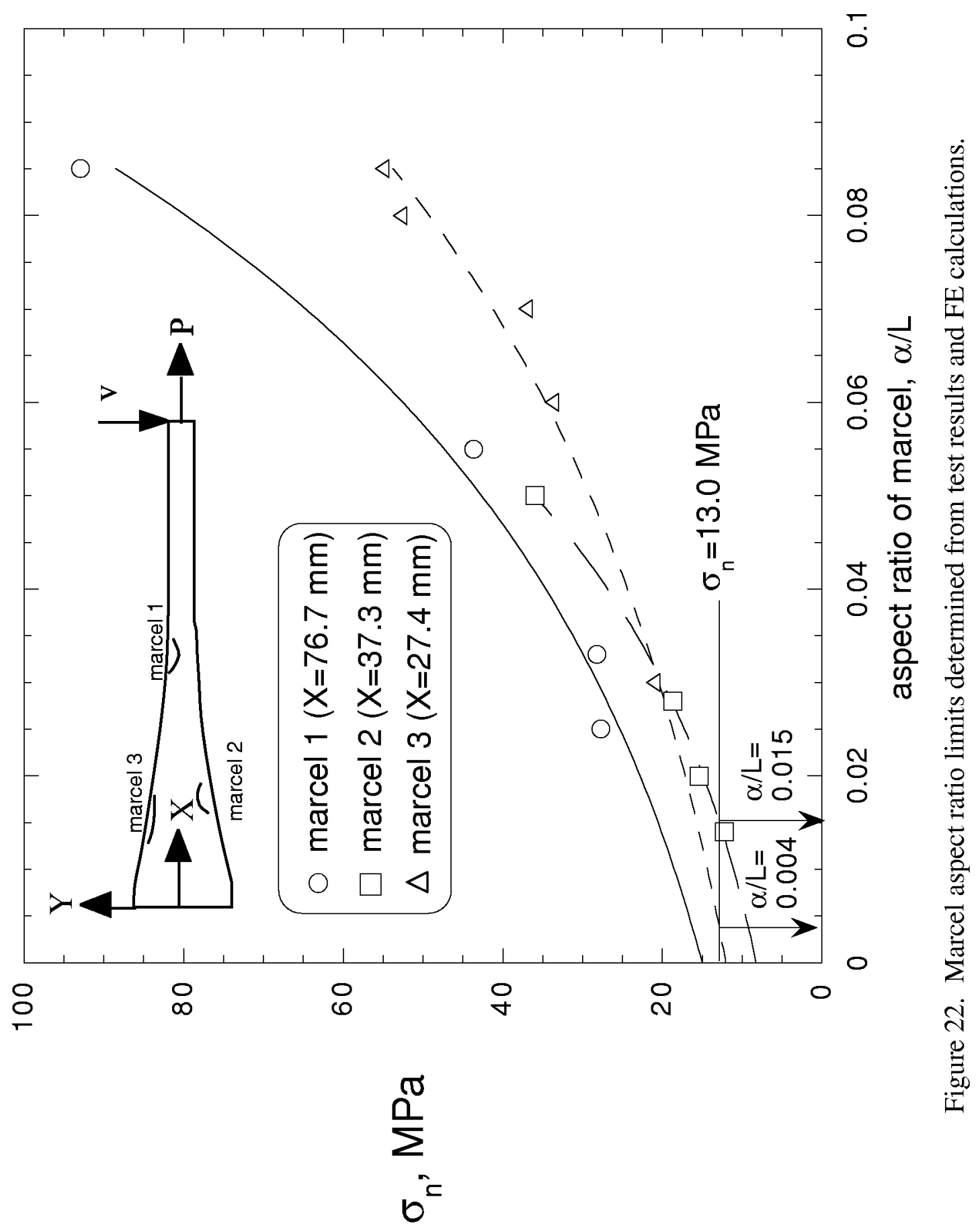




\begin{tabular}{|c|c|c|c|c|}
\hline \multicolumn{3}{|c|}{ REPORT DOCUMENTATION PAGE } & \multicolumn{2}{|r|}{$\begin{array}{l}\text { Form Approved } \\
\text { OMB No. 0704-0188 }\end{array}$} \\
\hline \multicolumn{5}{|c|}{$\begin{array}{l}\text { Public reporting burden for this collection of information is estimated to average } 1 \text { hour per response, including the time for reviewing instructions, searching existing data sources, } \\
\text { gathering and maintaining the data needed, and completing and reviewing the collection of information. Send comments regarding this burden estimate or any other aspect of this } \\
\text { collection of information, including suggestions for reducing this burden, to Washington Headquarters Services, Directorate for Information Operations and Reports, } 1215 \text { Jefferson } \\
\text { Davis Highway, Suite 1204, Arlington, VA 22202-4302, and to the Office of Management and Budget, Paperwork Reduction Project (0704-0188), Washington, DC 20503. }\end{array}$} \\
\hline 1. AGENCY USE ONLY (Leave blank) & $\begin{array}{l}\text { 2. REPORT DATE } \\
\text { December } 1999\end{array}$ & \multicolumn{3}{|c|}{$\begin{array}{l}\text { 3. REPORT TYPE AND DATES COVERED } \\
\text { Technical Memorandum }\end{array}$} \\
\hline \multicolumn{3}{|c|}{$\begin{array}{l}\text { 4. TITLE AND SUBTITLE } \\
\text { Influence of Ply Waviness on Fatigue Life of Tapered Composite Flexbeam } \\
\text { Laminates }\end{array}$} & \multirow{2}{*}{\multicolumn{2}{|c|}{$\begin{array}{l}\text { 5. FUNDING NUMBERS } \\
\text { WU 581-10-21-01 }\end{array}$}} \\
\hline \multicolumn{3}{|l|}{$\begin{array}{l}\text { 6. AUTHOR(S) } \\
\text { Gretchen B. Murri }\end{array}$} & & \\
\hline \multicolumn{3}{|c|}{ 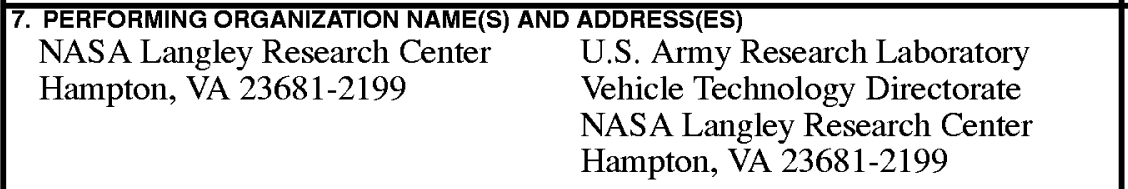 } & \multicolumn{2}{|c|}{$\begin{array}{l}\text { 8. PERFORMING ORGANIZATION } \\
\text { REPORT NUMBER } \\
\text { L-17908 }\end{array}$} \\
\hline \multicolumn{3}{|c|}{$\begin{array}{l}\text { 9. SPONSORING/MONITORING AGENCY NAME(S) AND ADDRESS(ES) } \\
\text { National Aeronautics and Space Administration } \\
\text { Washington, DC 20546-0001 } \\
\quad \text { and } \\
\text { U.S. Army Research Laboratory } \\
\text { Adelphi, MD 20783-1145 }\end{array}$} & \multicolumn{2}{|c|}{$\begin{array}{l}\text { 10. SPONSORING/MONITORING } \\
\text { AGENCY REPORT NUMBER } \\
\text { NASA/TM-1999-209830 } \\
\text { ARL-TR-2110 }\end{array}$} \\
\hline \multicolumn{5}{|c|}{$\begin{array}{l}\text { 11. SUPPLEMENTARY NOTES } \\
\text { Presented at the ASTM Symposium on Composite Structures: Theory and Practice in Seattle, Washington, on } \\
\text { May } 17-18,1999 .\end{array}$} \\
\hline \multicolumn{3}{|c|}{ 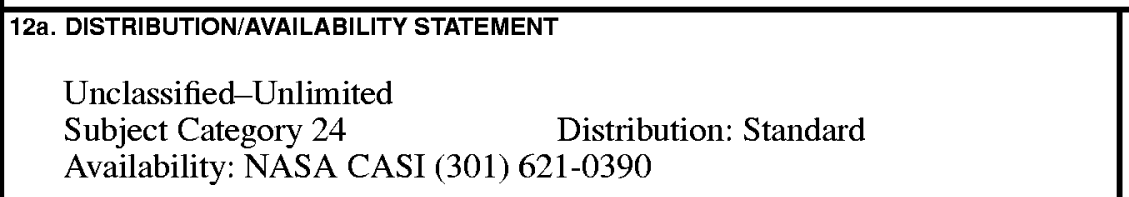 } & \multicolumn{2}{|c|}{ 12b. DISTRIBUTION CODE } \\
\hline \multicolumn{5}{|c|}{$\begin{array}{l}\text { 13. ABSTRACT (Maximum 200 words) } \\
\text { Nonlinear tapered flexbeam laminates, with significant ply waviness, were cut from a full-size composite rotor hub } \\
\text { flexbeam. The specimens were tested under combined axial tension and cyclic bending loads. All of the specimens } \\
\text { had wavy plies through the center and near the surfaces (termed marcelled areas), although for some of the speci- } \\
\text { mens the surface marcels were very obvious, and for others they were much smaller. The specimens failed by first } \\
\text { developing cracks through the marcels at the surfaces, and then delaminations grew from those cracks, in both } \\
\text { directions. Delamination failure occurred in these specimens at significantly shorter fatigue lives than similar spec- } \\
\text { imens without waviness, tested in ref. } 2 \text {. A 2D finite element model was developed which closely approximated the } \\
\text { flexbeam geometry, boundary conditions, and loading. In addition, the FE model duplicated the waviness observed } \\
\text { in one of the test specimens. The model was analyzed using a geometrically nonlinear FE code. Modifications were } \\
\text { made to the original model to reduce the amplitude of the marcels near the surfaces. The analysis was repeated for } \\
\text { each modification. Comparisons of the interlaminar normal stresses, } \sigma_{\mathrm{n}} \text {, in the various models showed that under } \\
\text { combined axial-tension and cyclic-bending loading, for marcels of the same aspect ratio, } \sigma_{\mathrm{n}} \text { stresses increased as } \\
\text { the distance along the taper, from thick to thin end, increased. For marcels of the same aspect ratio and at the same } \\
\text { X-location along the taper, } \sigma_{\mathrm{n}} \text { stresses decreased as the distance from the surface into the flexbeam interior } \\
\text { increased. A technique was presented for determining the smallest acceptable marcel aspect ratio at various loca- } \\
\text { tions in the flexbeam. }\end{array}$} \\
\hline \multirow{2}{*}{\multicolumn{3}{|c|}{$\begin{array}{l}\text { 14. SUBJECT TERMS } \\
\text { Marcel; Delamination; Flexbeam; Ply waviness; Finite element; Fatigue life }\end{array}$}} & & $\begin{array}{c}\text { 15. NUMBER OF PAGES } \\
39\end{array}$ \\
\hline & & & & $\begin{array}{l}\text { 16. PRICE CODE } \\
\text { A03 }\end{array}$ \\
\hline $\begin{array}{l}\text { 17. SECURITY CLASSIFICATION } \\
\text { OF REPORT } \\
\text { Unclassified }\end{array}$ & $\begin{array}{l}\text { 18. SECURITY CLASSIFICATION } \\
\text { OF THIS PAGE } \\
\text { Unclassified }\end{array}$ & $\begin{array}{l}\text { 19. SECURITY CLASSIF } \\
\text { OF ABSTRACT } \\
\text { Unclassified }\end{array}$ & FICATION & $\begin{array}{l}\text { 20. LIMITATION } \\
\text { OF ABSTRACT } \\
\text { UL }\end{array}$ \\
\hline NSN 7540-01-280-5500 & & & & $\begin{array}{l}\text { Standard Form } 298 \text { (Rev. 2-89) } \\
\text { Prescribed by ANSI Std. Z39-18 } \\
298-102\end{array}$ \\
\hline
\end{tabular}

